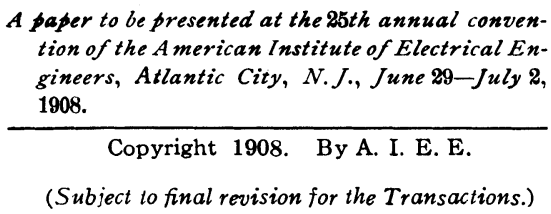

(Subject to final revision for the Transactions.)

\title{
A STUDY OF MULTI-OFFICE AUTOMATIC SWITCH- BOARD TELEPHONE SYSTEMS
}

\author{
BY W. LEE CAMPBELL
}

This paper treats of three principal topics:

1. The enormous economic waste which the wire, cable, and conduit equipment of a telephone system involves.

2. A recapitulation and discussion of reasons which make this waste necessary or expedient in manually operated systems.

3 . How this waste can and should be greatly reduced in systems employing automatic switchboards.

In other words, as most automatic switchboard plants have been installed in conformity with practices which emanated from experience with manual switchboard systems, the writer will discuss some of the reasons for these practices and endeavor to show that they can profitably be ignored in plans for automatic systems. To accomplish this he has made a study of the principal factors in the first cost of plants of both types, together with certain factors in their operating expenses. Since many telephone engineers have possibly not had an opportunity to study these factors, and would be much interested in a comparison of them, the writer has so arranged his data that they will be of use, not only in the discussion of his theme, but also in a determination of the measure of success which automatic switchboards have attained in furnishing the speedier, more uniform, and more economical service expected of them by the men who labored so hard and faithfully to develop them, and by the pioneers who had the courage to be their early purchasers and operators.

The first cost of a telephone plant using switchboards of either type may be divided into three principal items: 
1. Cost of the apparatus (both central office and subscriber's station).

2. Cost of the central office buildings and furnishings.

3 . Cost of the wire, cable, and conduit plant.

In the third item of the first cost-the wire, cable, and conduit plant-we find the largest factor of the three: The writer will not attempt, however, to give any average figures on the amount of this item. It is a variable quantity, depending in each system, not only upon the number of lines in the plant, but also upon the character of the soil, upon the average length of line as controlled by the density of population, by the form of the city, by the relative location of the business center or centers, and by obstructions, such as rivers, lakes, etc., and upon other similar conditions. Under almost any circumstances this part of the system will cost more than the two other parts combined; not infrequently it represents two-thirds of the entire first cost of the system.

It will, therefore, probably tax the credulity of engineers, whose experience has been in connection with electric power and lighting, when the writer states that in the average telephone system containing one central office only, nine-tenths of the cable and wire plant is idle-not in use for transmitting conversations, even at the peak of the load; and, too, that on the average during 24 hours' service, $98 \%$ of the wires are not in use. Yet such is the fact. Indeed, from observations made in a large number of automatic plants during the busiest hour, it was found that in offices of from 8,000 to 10,000 lines, handling a comparatively heavy traffic, the maximum number of conversations taking place at one time was equal to slightly less than $4 \%$ of the number of lines in service. As each conversation represents two lines, this would indicate a maximum of $8 \%$ of the lines engaged for conversation, operating and signaling at the peak of the load.

Excepting. party-line service, which at best is but a partial remedy, there is only one method known to telephone engineers of to-day for materially reducing the great economic waste represented in the $90 \%$ of the costly cable, wire, and conduit equipment which is not in use even during the "rush hours". This method is to divide up each plant so that instead of one large central office it will employ a number of smaller offices. Just how much saving ean be effected in this way, depends upon the local conditions in each city; but it will be readily 
understood that if small central offices or stations should be distributed over a city at the centers of well selected districts, the telephones in each district being connected only to the local station, the subscribers' lines would be decidedly shorter and cheaper than when all run for many blocks to a large centrally located office. For interconnecting between the district stations, only trunk lines would be needed, and it is necessary to have only enough of these to handle the busy-hour traffic; that is, the trunk lines need to be but a small percentage of the number of wires which would be installed if each telephone should be directly connected to one large central office.

An arrangement resembling that just outlined is in use in large cities, where of necessity some division has been made in manual systems for the reason that it is physically impracticable to terminate all lines in one multiple switchboard; that is, within the reach of each operator. Many telephone engineers do not consider it good practice to connect over 10,000 lines to one manual board, and while several boards have been installed with an ultimate capacity of 18,000 lines, the parts are so small and comparatively delicate that it is probable that repairs and depreciation will be exceedingly large items.

The writer does not wish to convey the idea that in manual practice systems are not divided up to save wire and cable; for in a very large city covering a great area this must be done. For example, in Chicago there are 15 or 16 central offices averaging about 3000 lines each. But division of an office of less than 10,000 lines is generally regarded as undesirable and to be avoided wherever possible. It is, therefore, the general practice in smaller cities to carry all or the bulk of the business on one large board, smaller branch boards being installed under suffrance and only for urgent reasons. The writer hopes to demonstrate that while this antipathy toward dividing offices of 10,000 lines or less is reasonable in manual practice, it is not reasonable in automatic practice.

Taking up the study of the factors that govern the first cost of a common-battery system of either type, and considering them in the order in which they have been named, we find first, that the cost of the ordinary direct-line, flat-rate telephone at the subscriber's station is about the same ( $\$ 7.25$ each) in all sizes and conditions of modern common battery manual plants, and $\$ 12.50$ each in automatic plants. The cost of a private branch switchboard at a subscriber's premises is not materially affected by 
the size, location, or type of the central office to which it is connected. This, therefore, will not be taken into consideration.

The cost of the central office equipment when all installed in one office depends upon the number of lines entering the office, and the number of connections demanded during the busy-hour of each day. No storage feature is possible in a telephone plant. The switchboard must be designed to take care of the peak of the load, no matter how exaggerated that peak may be.

For the purpose of this paper, the writer has drawn, as shown in Fig. 1, an arbitrary curve, $A$, from which will be taken all figures used on the number of calls made per line per day in

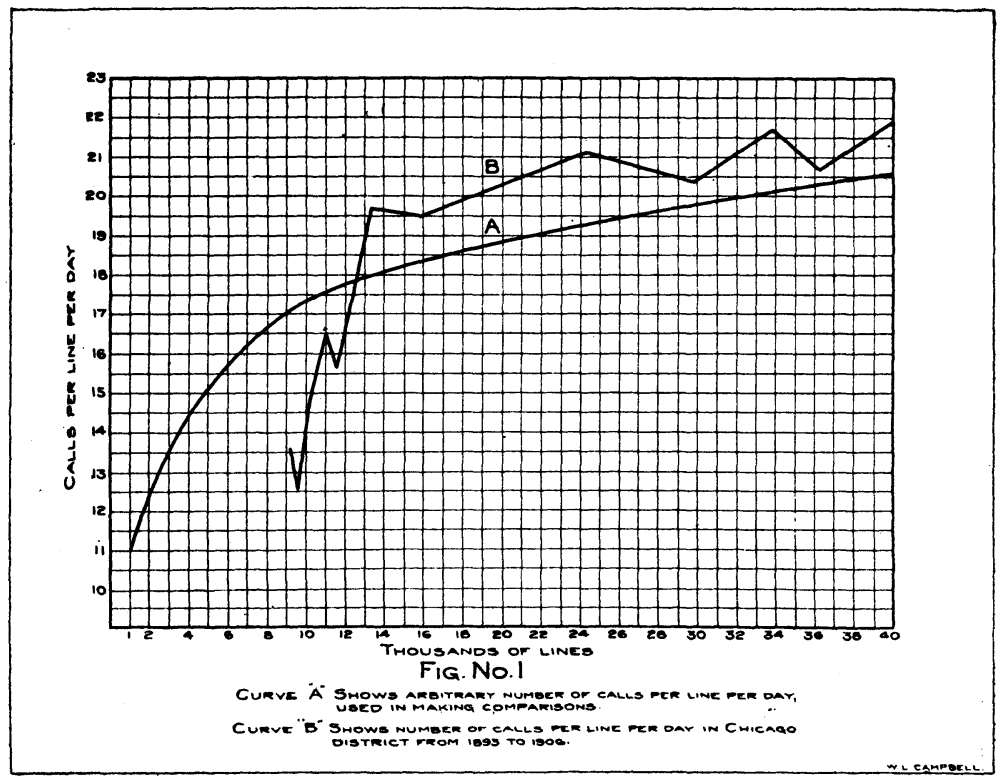

plants of different sizes. While this curve is not an unreasonable one, for flat-rate lines, it does not purport to be an exact average. Curve $B$ in Fig. 1 shows the growth in the average number of lines in service and in the average number of calls per line per day in the "Chicago district" of the Chicago Telephone Company during the series of years, from 1893 to 1906 . The writer supposes that the comparatively small traffic from 1893 to 1897 is largely due to the business depression then existing, and to the fact that the telephone had not then been sufficiently advertised to make it such an important factor, as it now is, in our business and social intercourse. 
It will also be taken for granted that the number of calls made during the busy hour of each day is one-eighth of the total day's business. Experience shows that this is an average ratio. The average busy-hour's work of an operator in the small manual plants is about 225 flat-rate connections; in the

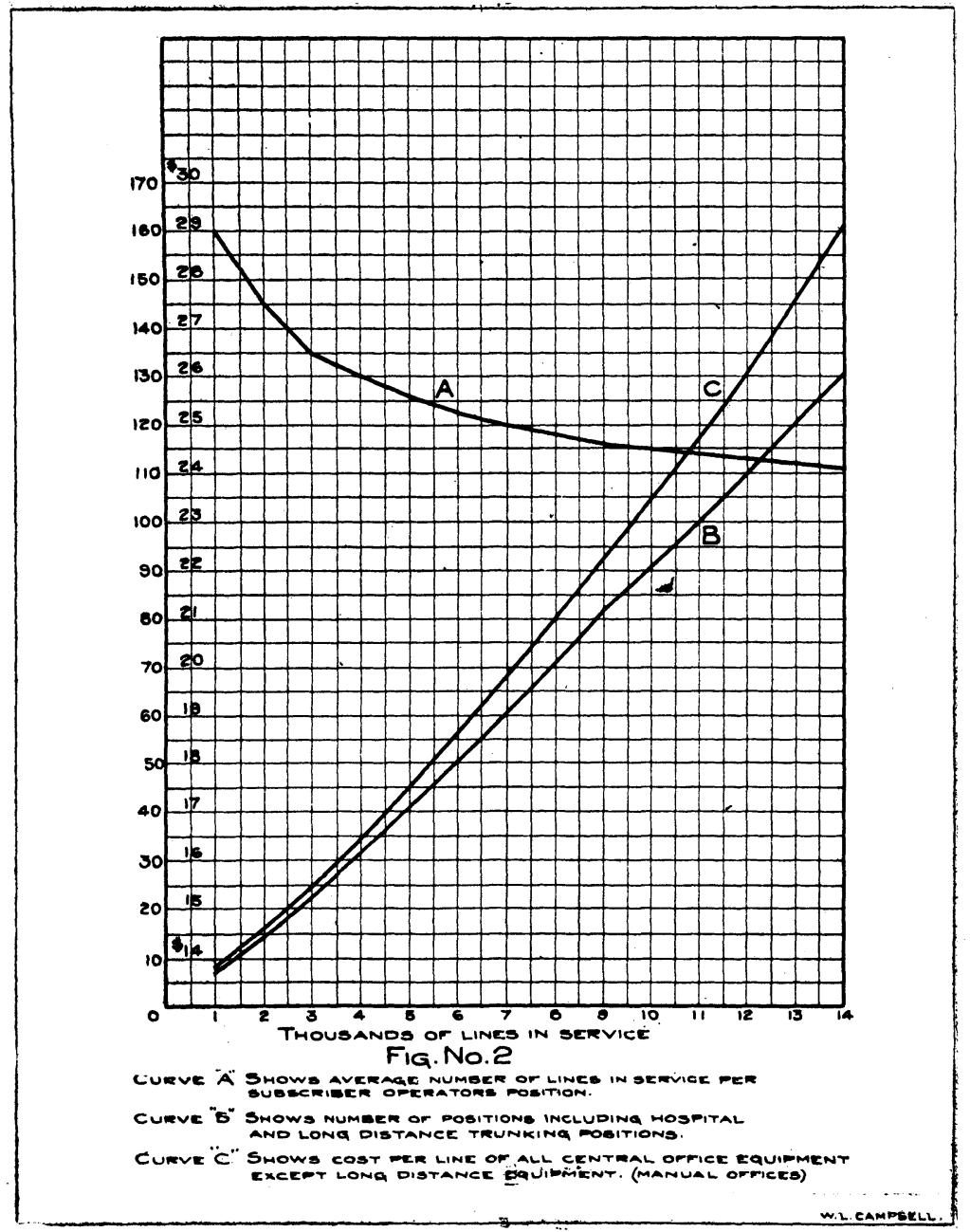

large manual plants about 250 flat-rate connections when no calls are trunked to other offices. In explanation of this difference in connections handled, it might be well to say that discipline is usually better in the larger offices, and consequently the operators do more work than in the smaller ones. 
With the foregoing points determined, curves $A$ and $B$, Fig. 2, have been constructed. Curve $A$ gives the number of flat-rate lines per operator's position, and $B$ the number of operators' positions for manual switchboards equipped for

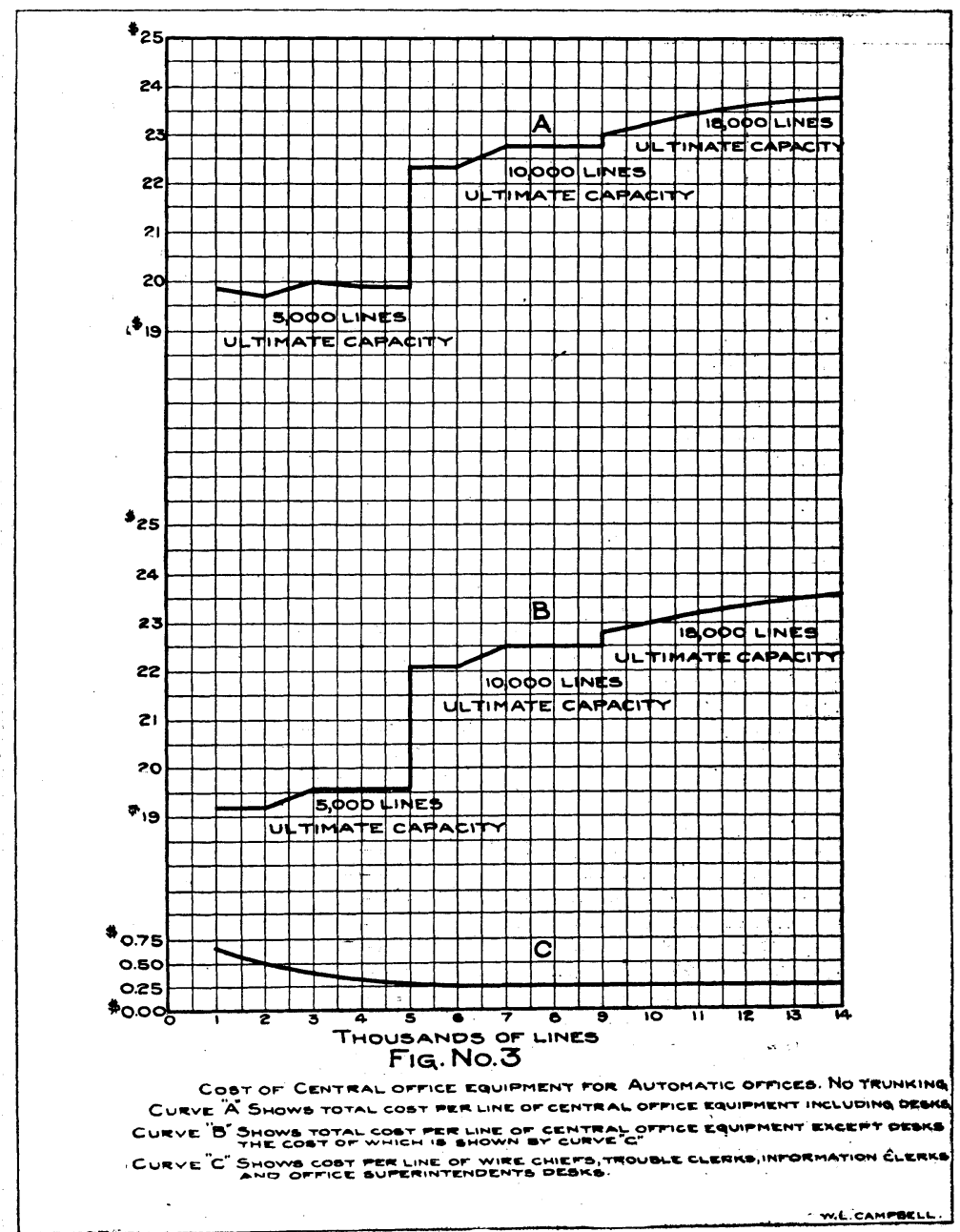

from 1,000 to 14,000 lines, and for handling the number of calls per line per day indicated by curve $A$, Fig. 1 . Curve $C$ was then constructed, using the figures represented by curves $A$ and $B$ and the average prices at which a number of modern, well constructed, manual central office equipments using com- 
mon-battery multiple switchboards have been sold and installed.

Curve $A$ in Fig. 3 gives the cost installed of automatic central office equipment for offices of from 1,000 to 14,000 lines, designed to handle the number of calls per line per day as given by curve $A$, Fig. 1. The cost of central office equipment of either type includes cost of terminal racks, power plant, wire chief's, information clerk's and trouble clerk's desks; in short, all apparatus except a long-distance board and its accessories. In making up the figures on the cost of automatic equipment, the number of trunking switches. necessary per hundred lines for handling

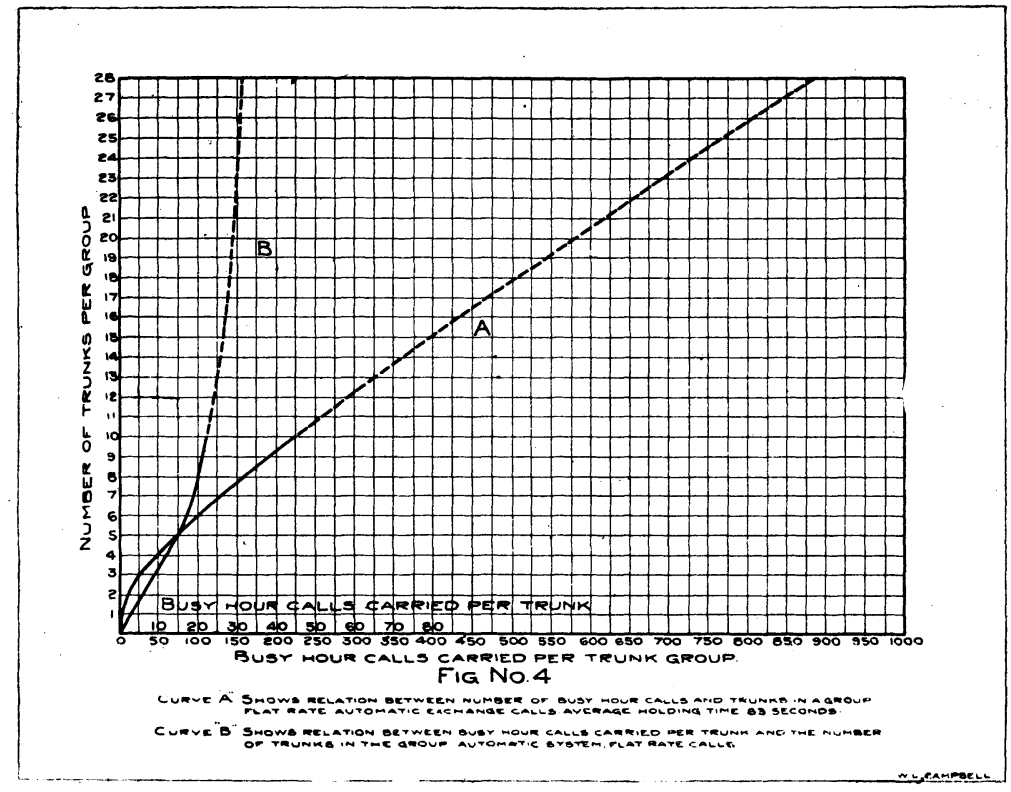

the busy-hour traffic was taken from curve $A$, Fig. 4 . This curve, which is the result of thousands of observations made in automatic offices, follows the empirical formula:

$$
\text { Trunks }=T C+2.8 \sqrt[3]{T C}
$$

in which $T$ represents the length in hours of the average connection and $C$ represents the number of busy-hour calls.

For the benefit of those not familiar with automatic switchboards, the writer will state that each line terminates in what is generally called a line switch. These line switches are arranged 
and multiplied together in groups of 100 each. Connections between these groups are made by means of trunking switches called first selectors, second selectors, third selectors, and connectors. In a system having an ultimate capacity of 1000 lines, first selectors and connectors are the only trunking switches used. When the ultimate capacity is increased to 10,000 lines, second selectors are required also; and when the ultimate capacity is increased to 100,000 lines, third selectors are added. In a 100,000 -line system, then, there is one first selector, one second selector, one third selector, and one connector for each trunk equipped.

A system with an ultimate capacity of 18,000 lines is made by installing a section of switchboard equipped for 8000 lines and arranged for an ultimate capacity of 10,000, and another section of switchboard equipped for the remaining 10,000 lines and using third-selector switches as if installed for an ultimate capacity of 100,000 lines. Such a combination does not involve any complications and makes the cost less than if the entire equipment were arranged for an ultimate capacity of 100,000 lines.

The cost of banks for ten selector switches of each type, and of ten connector switches per hundred lines, was included in all figures to allow margin for the practice, recently introduced into automatic plants, of moving selector and connector switches about from comparatively idle to busier sections in order to handle the busy-hour traffic with the least possible number of trunking switches. This practice is similar to that common in manual plants of apportioning the work among the operators' positions by means of an intermediate distributing frame.

In comparing these two first-cost curves ( $C$ in Fig. 2 and $A$ in Fig. 3), it will be seen that the cost per line of manual equipment increases rapidly with the size of the office. This increase is principally due to the greater and greater number of multiple jacks which must be placed within each operator's reach, whereas, since the automatic is a trunking system, the cost per line is affected only by the slow growth in the number of trunks necessary to handle the busy-hour calls, and, at intervals, an increase in the ultimate capacity of the switchboard. The price of this equipment, therefore, rises more gradually and in the larger offices falls below that of the manual type.

For comparison only, the writer shows in curves $A$ and $B$, 
Fig. 5, the respective costs of manual and automatic central office equipment as given by curve $C$, Fig. 2 , and $A$, Fig. 3 , plus the cost of one telephone per line.

Taking up the second item of first cost for single office systems, the writer would direct attention to Fig. 6 in which curves $A$

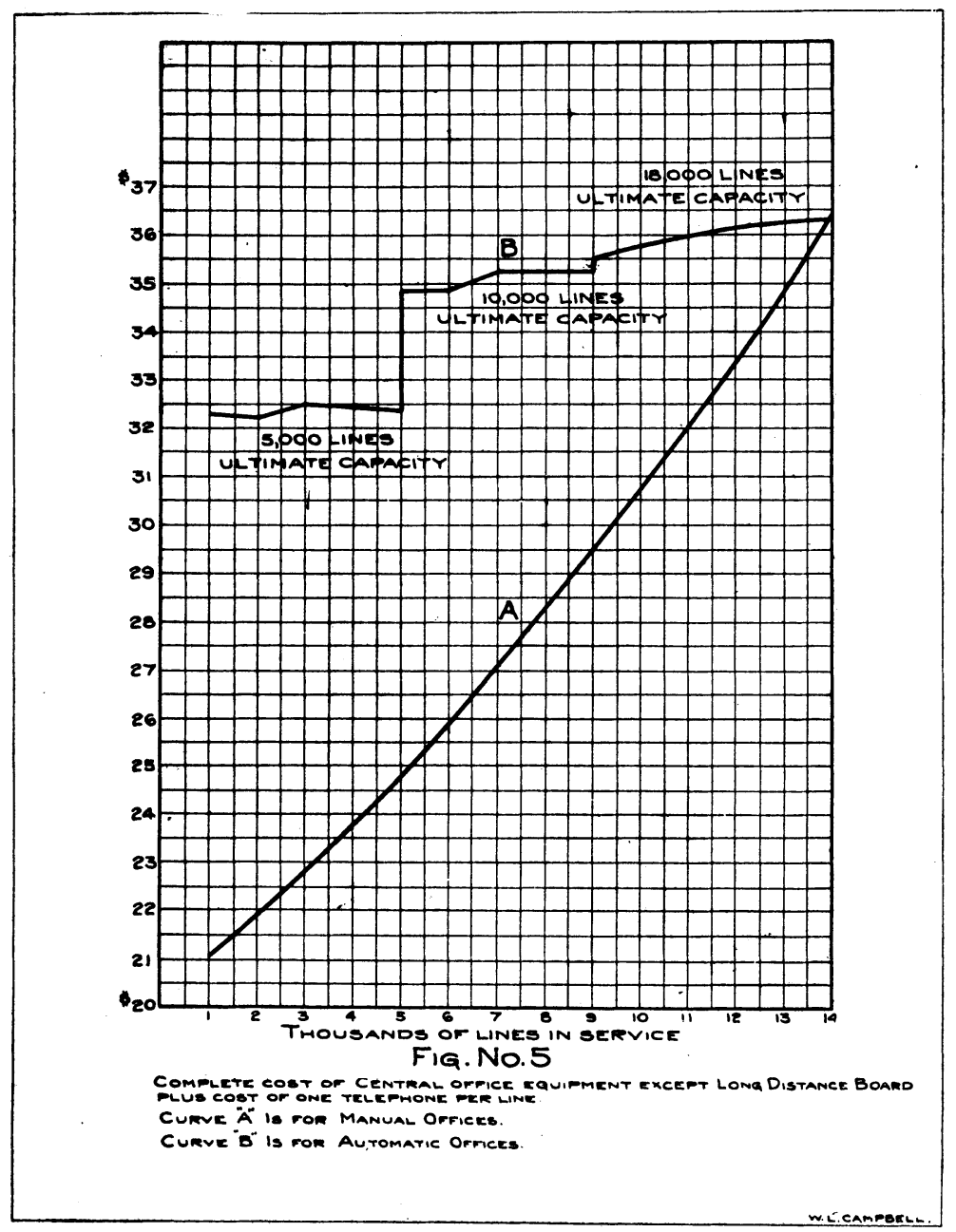

and $B$ give the square feet of floor space required on the average for automatic and manual central office equipments respectively. Curve $C$ gives the cubic feet of space required for automatic equipment, and curve $D$ gives the cubic feet of space required for manual equipment. In this same figure, curve $E$ for automatic 
equipment and curve $F$ for manual equipment give the first cost of the necessary space in fire-proof buildings at an estimated rate of 19 cents per cubic foot for housing the automatic and manual equipments indicated. The cost of furnishings

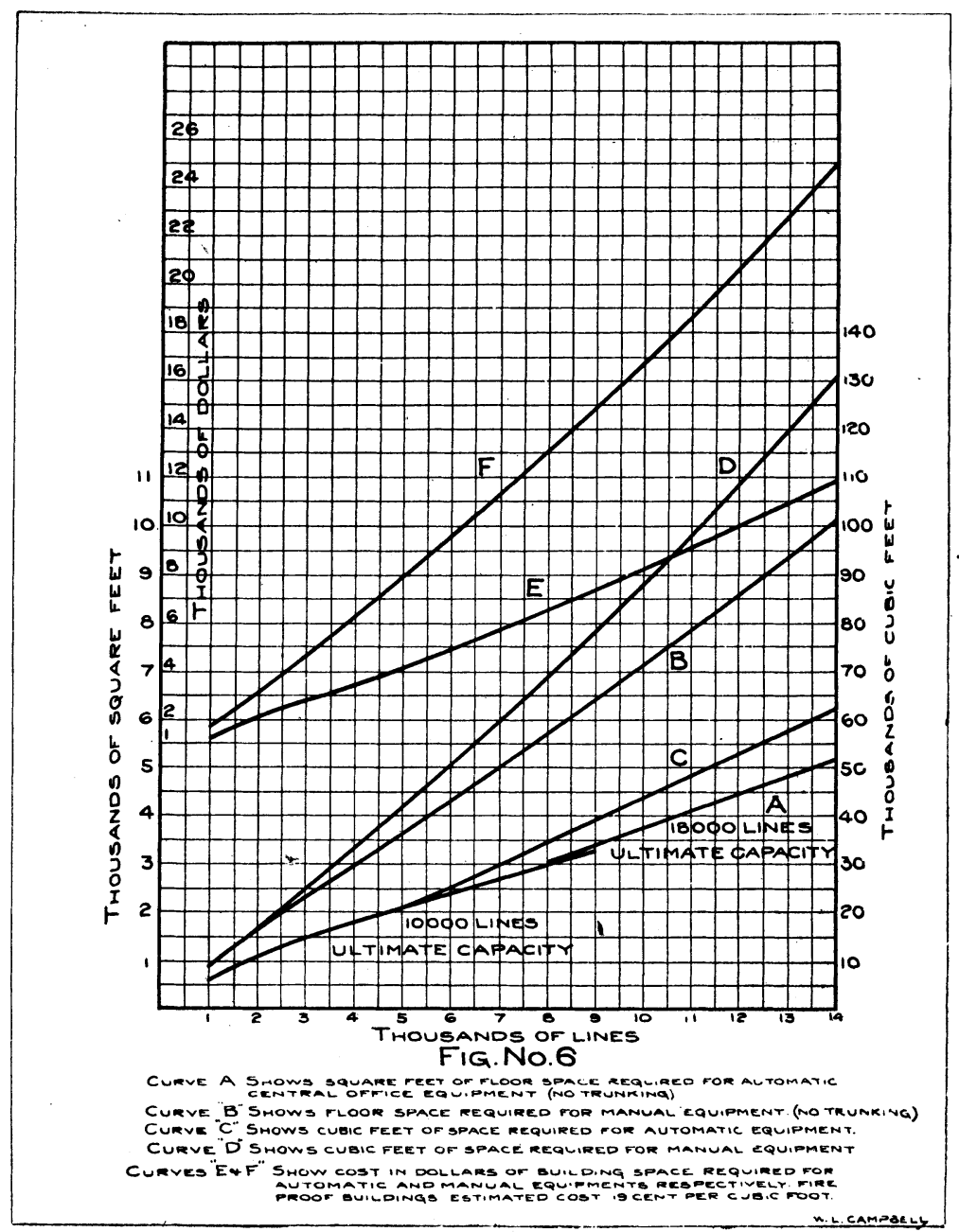

and land, and cost of space used for executive offices, storage, etc., are not included, nor is the cost of space usually allowed for a growth of at least $20 \%$ or $25 \%$ in switchboards included. The figures do, however, include the cost of space for operators' rest rooms, hospital, dining room, kitchen, etc. 
It will be noted that the cost of building space for automatic equipment is considerably less than that for manual equipment, and that for offices of over 5000 lines the automatic occupies about half the space required for the manual. No

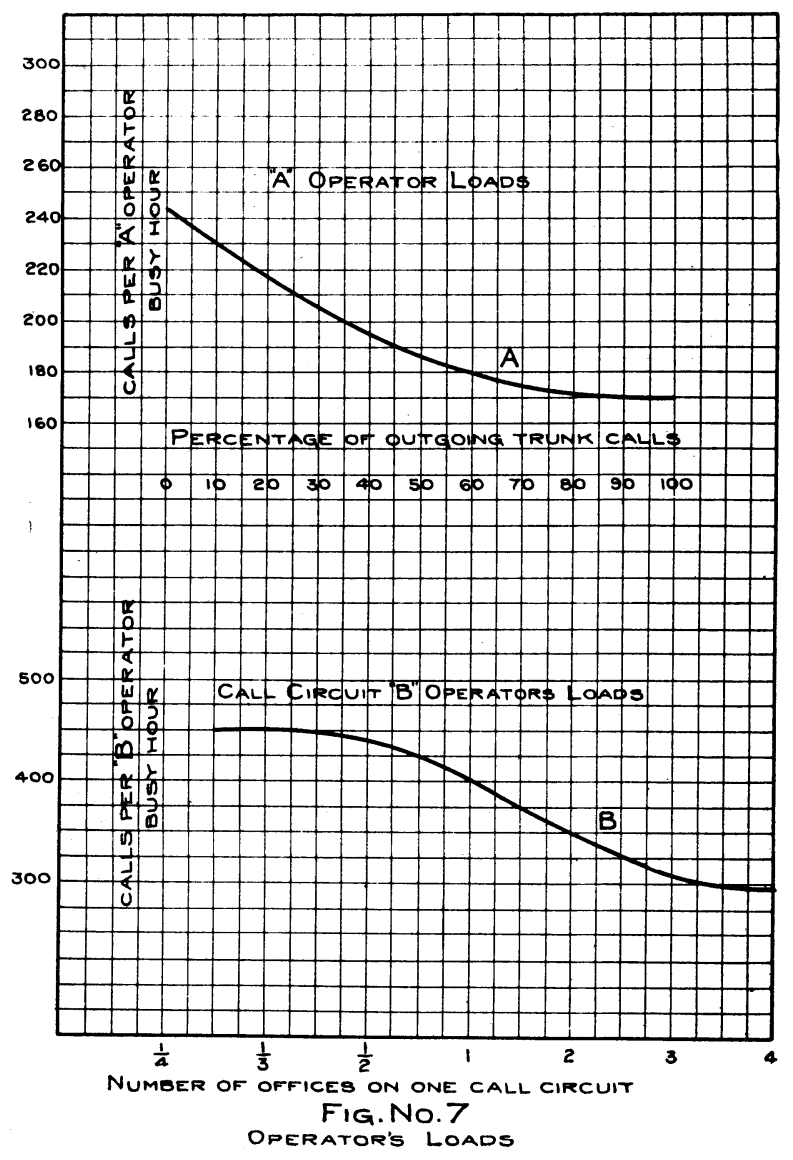

W.L. CAMPE

effort has been made to secure comparative figures on the cost of furnishings, but they are unquestionably more expensive in manual offices, since here recreation and rest rooms, restaurant, kitchen, etc., are commonly furnished and equipped for the use of the operators. In automatic offices the number of employees 
is comparatively small and the men are in the majority, consequently, it is not customary to make any elaborate provision for their comfort when off duty.

Having now shown what the average costs of the central office equipments and buildings would be in single office plants

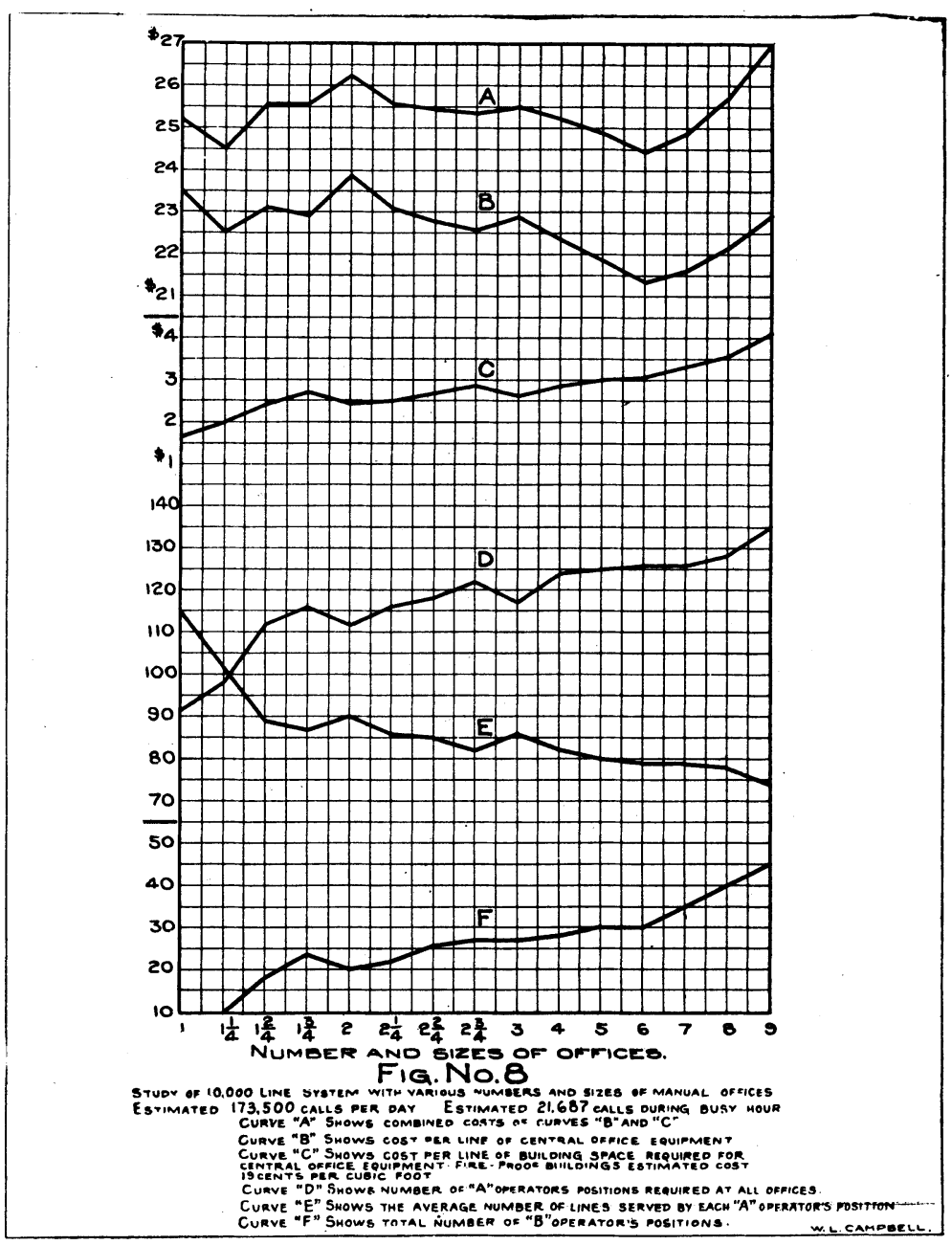

handling the traffic indicated by curve $A$, Fig. 1 , it is next in order to see what effect dividing up a system so that it employs more than one office, has on these two items of first cost.

In manual systems an operator's daily quota of connections is reduced when part of the calls which she handles must be 
trunked to other offices. This effect of trunking on the operator's work is indicated by curve $A$, Fig. 7 , which gives the number of flat-rate busy-hour connections which one of the largest manual operating companies has found that an average " A " operator will make with various percentages of trunked calls. It is, therefore, necessary in a multi-office manual system to install and to provide space for more " A " operators' positions, as well as to install and provide space for " B " operators' positions and to provide increased space for rest rooms, etc.

As an illustration, in Fig. 8, curves $D, F$, and $E$ show respectively the number of "A " operators' positions, the number of " B " operators' positions, and the average number of lines per " A" operator's position for a hypothetical 10,000-line system with different numbers and sizes of offices. The numerals along the bottom of the figure which indicate the various numbers and sizes of offices, have the following significance:

\begin{tabular}{|c|c|c|}
\hline \multicolumn{2}{|c|}{$1 \frac{1}{4}$ represents } & $\{1$ office of 8000 lines \\
\hline & “ & $\left\{\begin{array}{l}1 \text { office of } 6700 \text { lines } \\
2 \text { offices of } 1650 \text { lines each }\end{array}\right.$ \\
\hline & " & $\left\{\begin{array}{l}1 \text { office of } 5725 \text { lines } \\
3 \text { offices of } 1425 \text { lines each }\end{array}\right.$ \\
\hline & “ & 2 offices of 5000 lines each \\
\hline & “ & $\left\{\begin{array}{l}2 \text { offices of } 4450 \text { lines each } \\
1 \text { office of } 1100 \text { lines }\end{array}\right.$ \\
\hline & " & $\left\{\begin{array}{l}2 \text { offices of } 4000 \text { lines each } \\
2 \text { offices of } 1000 \text { lines each }\end{array}\right.$ \\
\hline & esents & $\left\{\begin{array}{l}2 \text { offices of } 3650 \text { lines each } \\
3 \text { offices of } 900 \text { lines each }\end{array}\right.$ \\
\hline & “ & 3 offices of 3333 lines each \\
\hline & “ & 4 offices of 2500 lines each \\
\hline & “ & 5 offices of 2000 lines each \\
\hline & “ & 6 offices of 1667 lines each \\
\hline & “ & 7 offices of 1429 lines each \\
\hline & “ & 8 offices of 1250 lines each \\
\hline & “ & 9 offices of 1111 lines each \\
\hline
\end{tabular}

It will be noted that the number of " $A$ " and the number of " B" operators' positions grows quite rapidly as the number of offices is increased, while the number of lines per "A" operator's position diminishes.

In working out these curves the percentage of outgoing trunk 
calls from any office was calculated by the formula; trunking $\%=$ $100 \frac{A-B}{A}$ multiplied by 0.75 ; where $A$ is the total number of lines in the system, $B$ equals the number of lines in the office under consideration and 0.75 is a factor which experience in-

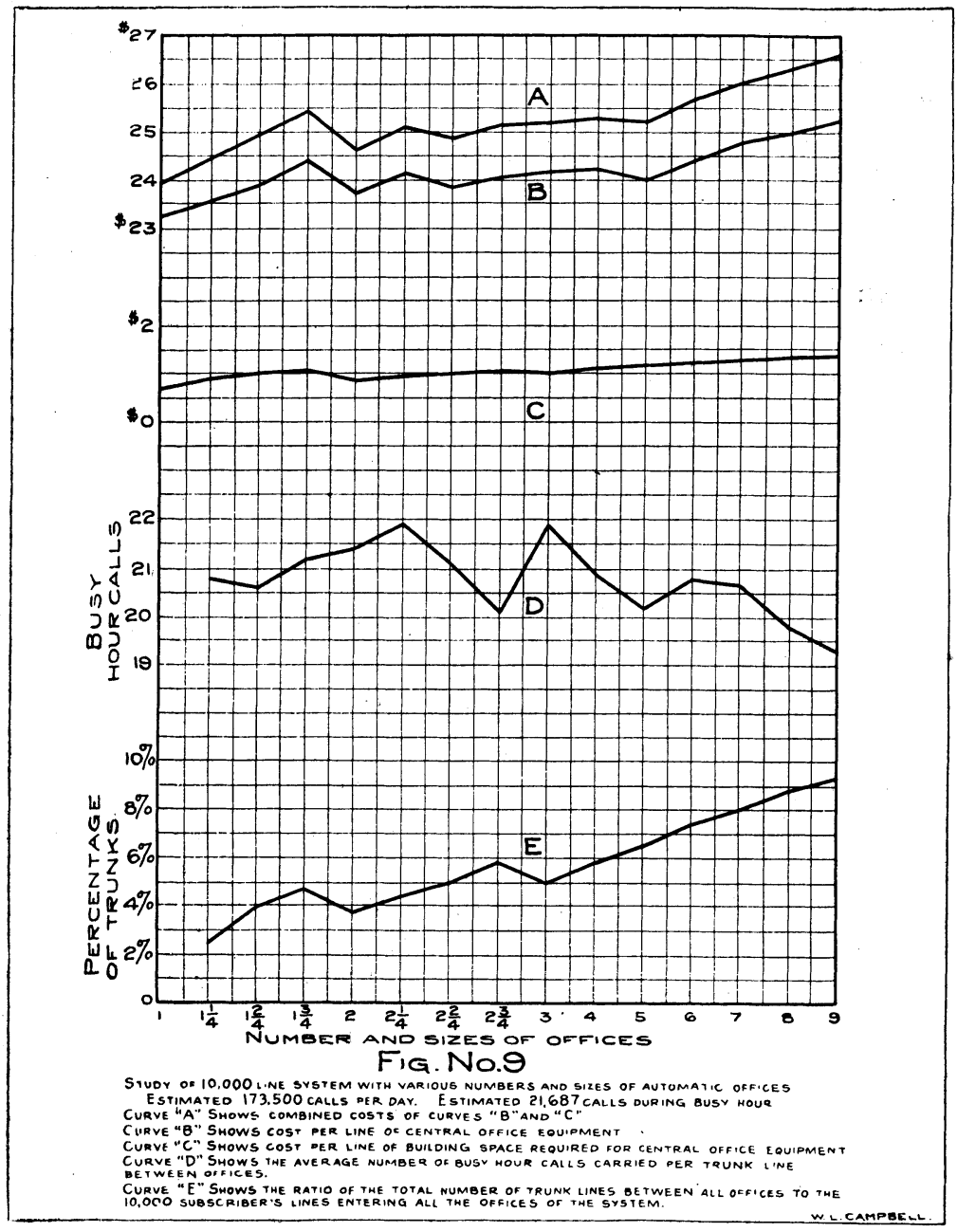

dicates will allow under average conditions for the community of interest between the subscribers in an office district. Of course, in a study of a particular locality this factor should, if possible; be accurately determined; it may be as small as 0.4 or as large as $\mathbf{1 . 5}$. 
Curve $B$, Fig. 8 , gives the approximate cost per line of the central office equipments installed as derived from the data used in curves $D, F$, and $E$ previously mentioned. It will be noted that although more positions are necessary than in a single office, the cost of each position is reduced by a decrease in the line equipment and in the number of multiple jacks per position, so that there is not a great variation in the total switchboard cost. In the same Fig. 8, curve $C$ shows the cost per line of the buildings for the various sizes and numbers of offices in the divided system. The cost of space required for executive offices, storage, etc., is not included in these figures, nor do they include the cost of land and furnishings. Curve $A$ shows the combined cost per line of central office equipment and build-

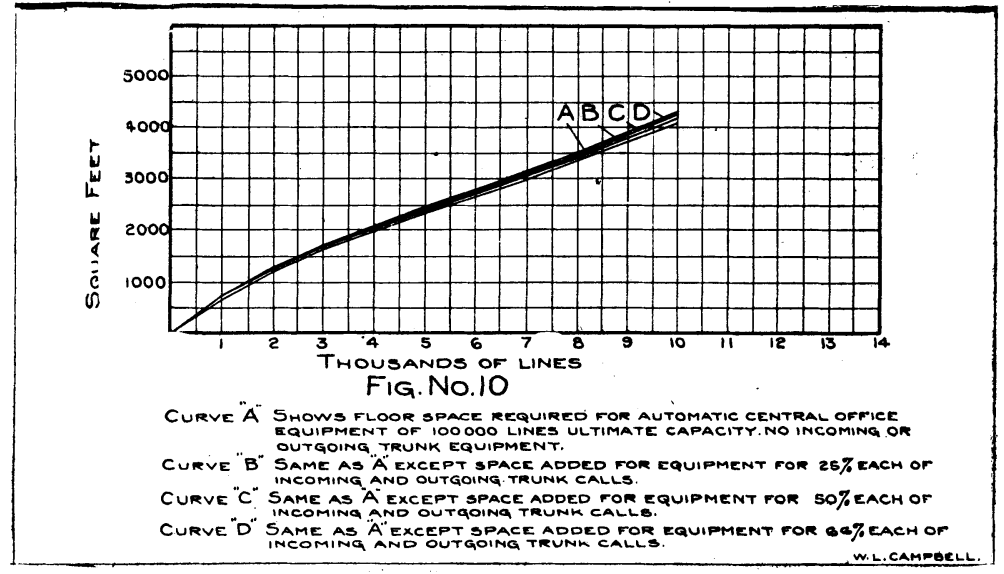

ings. It will be noted that the greater cost of buildings is, to some extent, counterbalanced by a reduction in the cost of the equipment. The small increase would in any event be. of little moment in comparison with the saving in the cost of the wire, cable, and conduit plant, which might be secured by plant division. It would, therefore, appear that we must look further for the cause of the objections to multi-office manual systems.

Before discussing operating expenses, however, let us see what effect plant division has on the first cost of automatic central office apparatus and buildings. To illustrate the effect, the curves in Fig. 9 have been worked out, using the same 10,000line system and the same numbers and sizes of offices employed in Fig. 8 for the manual system. The cost, installed, of central office equipment is somewhat increased by division, as will be 
noted by reference to curve $B$. The central office space required is also greater, as shown by curve $C$, Fig. 9 , and by curves $A$, $B, C$, and $D$, Fig. 10 . The slow increase in the combined cost of equipment and building as more offices are added is shown by

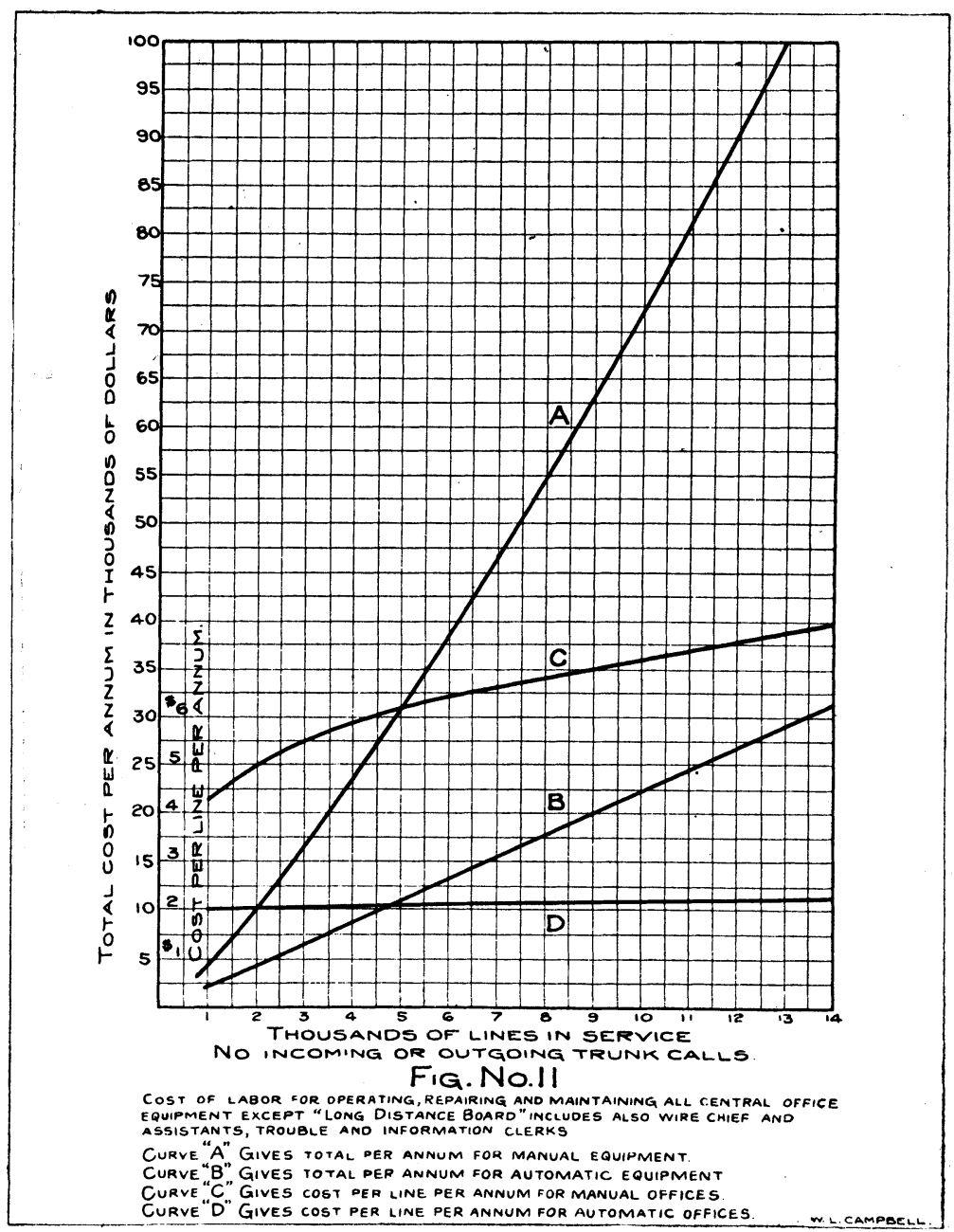

curve $A$, Fig. 9. The increases are of small import in comparison with the saving in the underground and aerial construction secured by using a larger number of offices.

Taking up the subject of operating expenses, the writer would direct attention first to curves $A$ and $C$, Fig. 11, which show 
average annual operating and maintenance labor cost for manual central offices of from 1000 to 14,000 lines, doing no trunking and handling the number of calls per line per day indicated by curve $A$, Fig. 1 . Curves $B$ and $D$, Fig. 11, show respectively the total annual cost and the annual cost per line of all central office labor for automatic offices of from 1000 to 14,000 lines. These figures are averages of the labor costs obtained from a considerable number of automatic switchboard operating companies.

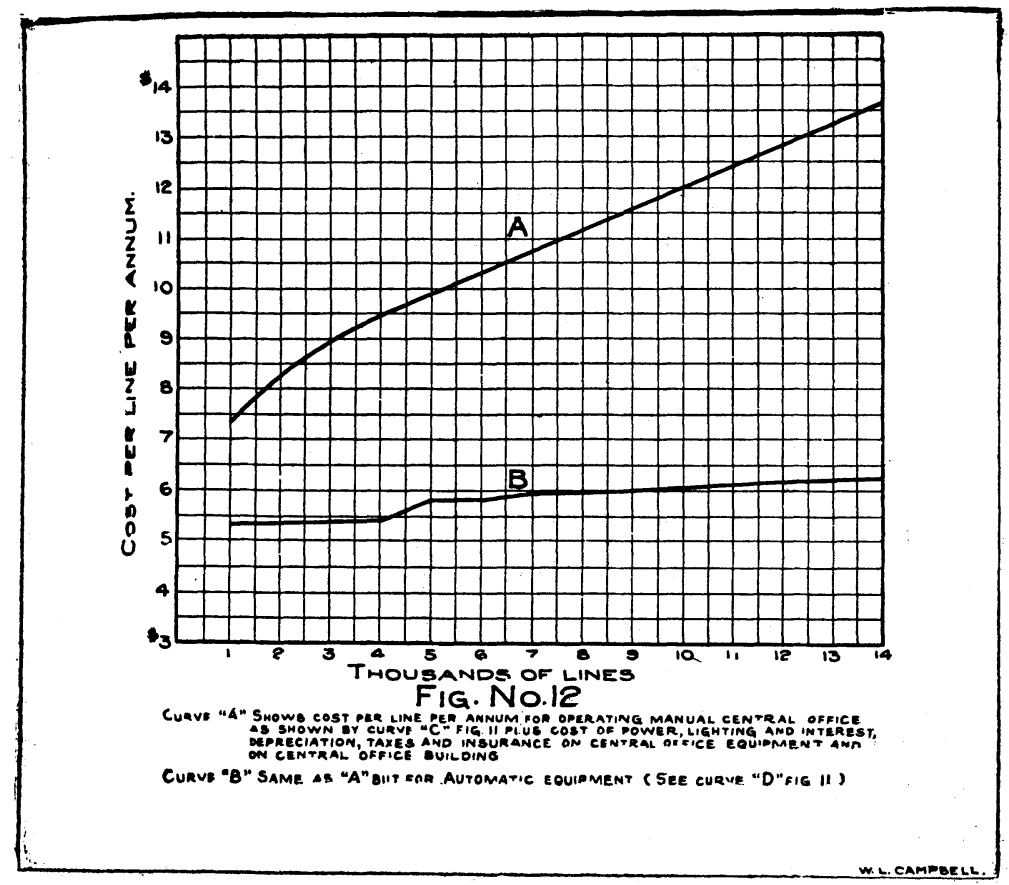

The writer would next direct attention to curves $A$ and $B$, Fig. 12, which give the central office labor expense as shown in Fig. 11, plus the cost per line per annum of certain central office equipment and central office building charges that are materially affected by plant division. Curve $A$ is for manual offices of from 1000 to 14,000 lines, no trunking, and curve $B$ gives similar data for automatic offices. These figures include insurance, taxes, interest and depreciation on central office equipment and buildings, renewals for central office equipment, and the cost of lighting and power. 
Insurance of the central office equipment in fire-proof buildings is taken at $1 \%$ per annum. Although several companies operating automatic apparatus have informed the writer that they secured a lower rate than that which they could get on manual equipment, it does not appear that the rating authorities have made any general rule which would assure a reduction. Since, however, much of the damage done to switchboards by fire is caused by blazes originating within the apparatus itself, and since the insurance companies exempt themselves from losses caused by such blazes, it would seem that fire losses would be smaller with automatic equipment than with manual. Manual switchboards are largely built of inflammable material and are incased in wooden cabinets. Also, if a blaze should start in one end of a manual board, there is little in the construction of the board to prevent it from sweeping through the entire length. Automatic switchboards are divided up into small separated sections so that a blaze in one would have very little opportunity to leap across to another. The apparatus itself is made up almost entirely of metal.

Taxes on both types of equipment are figured at the rate of $1.5 \%$ per annum; interest is figured at $6 \%$ per annum for both.

Depreciation on manual central office equipment is figured on an average life of 10 years. Of course, many parts of the switchboard must be replaced in less time: for example, cords in an average time of 1.5 years, plugs in 2 years, keyboard lamps 3 years, answering jacks 5 years, etc. These, however, are believed to be covered by including a $2 \%$ charge for maintenance materials and renewals. Depreciation on automatic equipment is calculated on a life of 12 years. Although no automatic plants, to the best of the writer's knowledge, have been in continuous service for this length of time, he has found that plants which have been in operation for 7 or 8 years show very little wear. While some such plants have been replaced by new ones, it has been because it was believed that better service and decreased operating costs, made possible by the new and improved equipment obtainable at the time the change was made, would pay for making it before the life of the original plant was exhausted. As an example, showing the effect of wear and tear on an automatic switchboard, there is in Fall River, Mass., an automatic plant which has been in operation for 7 years; at this plant the only appreciable wear is on the shaft wipers of the busier trunking switches. While these wipers could be 
renewed at a very modest expense, they will apparently last for some years yet. The wear on the equipment, which is individual to each subscriber's line, is hardly noticeable. In fact, an automatic switchboard has never been known to wear out, while manual switchboards are really worn out by the continued use of the parts by the operators. As the writer has already stated, such manual switchboard parts as cords, keyboard lamps, answering jacks, trunk jacks, etc., will need to be replaced at intervals during the life of the board. It is also found that the keyboards and plug shelves made of wood and sole leather become so worn from the continual contact of the operators fingers and the rubbing of the cords, and so battered by the constant pounding of the plugs, that they must be replaced in 6 or 7 years on a very busy board. In 10 years, or sometimes even less, the keys, multiple jacks, multiple cables, etc., are generally in such condition that it becomes necessary to replace the entire switchboard, regardless of whether it has become obsolete or not.

Ten to fifteen years ago telephone apparatus was being developed so very rapidly that the life of a board was not more than 5 or 6 years. At the end of that time the board would be so out-of-date that competition or a proper regard for service or for operating expenses would usually compel its replacement by a more modern one. That time ended in manual practice with the perfection and introduction of the common-battery multiple board. No radical improvements have since been made. Automatic switchboards have also reached a somewhat similar plane of development. For illustration, in the Fall River system installed in 1901, a subscriber makes a call by means of a dial, and secures service very similar to that in the most modern plant. Looking at the automatic switchboard itself, we find the so-called grouping system, the automatic selection of trunks, push-button ringing, and other essential features of the latest equipment. It is true that great improvements have been made in automatic equipment in very recent years, such as the introduction of common-battery service, party lines, line or individual switches, improved methods of manufacture, installation, etc., but these are all points which appeal to the manufacturer or to the operating company, while improvements in the general appearance of the telephones are about the only ones made in the last 7 or 8 years which are of much interest to the telephone users. Therefore, consider- 
ing service only, and viewing the matter from the standpoint of the telephone subscriber, the writer believes it reasonable to conclude that there is little probability, in the near future, of a manual switchboard being rendered obsolete by a more improved manual board or of an automatic switchboard being put out of the arena by an automatic switchboard giving better service. He, therefore, has taken the life of a manual switchboard at the full amount that a consideration of wear and tear only will permit; and, in order to be perfectly conservative, has placed the life of an automatic board at but 2 years longer although there is no reason to suppose that it would not still be good for a number of years of service at the end of that time. The amount which must be set aside annually at $6 \%$ compound interest to equal $100 \%$ in 12 years is $6 \%$ of first cost. Therefore, this percentage is used in calculating depreciation on automatic central office equipment, while for manual equipment the depreciation charge is taken at $7.5 \%$, which is the amount which must be set aside annually at $6 \%$ compound interest to equal first cost in 10 years.

Looking into the matter of maintenance material or renewals for automatic central office equipment, the writer has found from an investigation of a number of automatic plants that the renewals for the switchboard proper amount on the average to $0.2 \%$ per annum on the first cost of the central office equipment. The power plant, main distributing frame, and other parts of the central office equipment, increase the renewals item, however, and in order to cover everything it has been taken at $0.5 \%$ for automatic offices.

The cost of power per originating call handled is about twice as much for automatic switchboards as for most of the manual switchboards used by the "independent companies". The amount of current consumed is almost the same, 0.006 of an ampere-hour. Automatic plants generally use a battery of 46 volts, about twice the voltage of the usual manual battery, although in large plants where the lines are long, 40-volt batteries are sometimes employed in manual practice. The manual switchboards generally used by the Bell companies require considerably more current than those used by the independent companies. The amounts used by the independent boards have been taken in working out the curves in this paper. Taking the cost of power, transformed and delivered at the switchboards, at $15 \mathrm{cts}$. per kilowatt-hour gives a cost of $\$ 0.0216$ per 
thousand local calls for manual offices and of $\$ 0.0432$ per thousand local calls for automatic offices. The additional cost per thousand incoming trunk calls received at a manual office would be $\$ 0.0144$. For automatic offices the additional cost for incoming trunk calls would be $\$ 0.004$ per thousand, assuming that the number of calls trunked out from an office equals the number incoming.

The cost of lighting automatic central office equipment has been taken at $\$ 4.00$ per thousand lines per month; and for manual offices the cost of lighting the operators' positions, the switchboard rooms, operators' retiring rooms, terminal room, desks, etc., has been taken at $\$ 2.00$ per switchboard position per month.

The annual charges on the central office buildings have been taken at the same rates for the two systems; that is, insurance on fire-proof central office buildings has been figured at $0.5 \%$ per annum, interest at $6 \%$, taxes at $1 \%$, and depreciation and repairs at $2 \%$ per annum.

In order to illustrate the effect on the annual expenses, just discussed at length, caused by dividing a system up so that it employs a number of offices instead of one, the writer has constructed the curves in Fig. 13, which show what the expenses would be for the different numbers and sizes of offices in the hypothetical 10,000-line system used in Figs. 8 and 9 . Referring to curve $A$ in Fig. 13, it will be noted that the annual cost of central office labor for the nine-office arrangement of the manual system is $80 \%$ greater than for the single office arrangement.

It might be stated just here that the item of operators' hire is one which yearly grows to greater magnitude. One very large telephone operating company instructs its engineers engaged in development studies to estimate on operators salaries being at least $15 \%$ higher 15 years hence.

Curve $B$, Fig. 13, shows that the increase in the cost of labor plus the annual charges on equipment and buildings, weighs heavily against the division of manual systems. In fact, experience shows that where the ultimate number of subscribers that may be expected in an office district within fifteen years does not exceed the capacity of a single multiple board (about 10,000 lines) and there is no concentrated group of subscribers at a considerable distance from the best location for a single office, it is generally found that a one office system will be the most economical when manual equipment is used. 
There are conditions under which it is profitable to divide manual 10,000 line plants; that is, there are conditions under which the saving in the annual charges on cable, wire and conduit, will more than offset the increase in central office expenses,

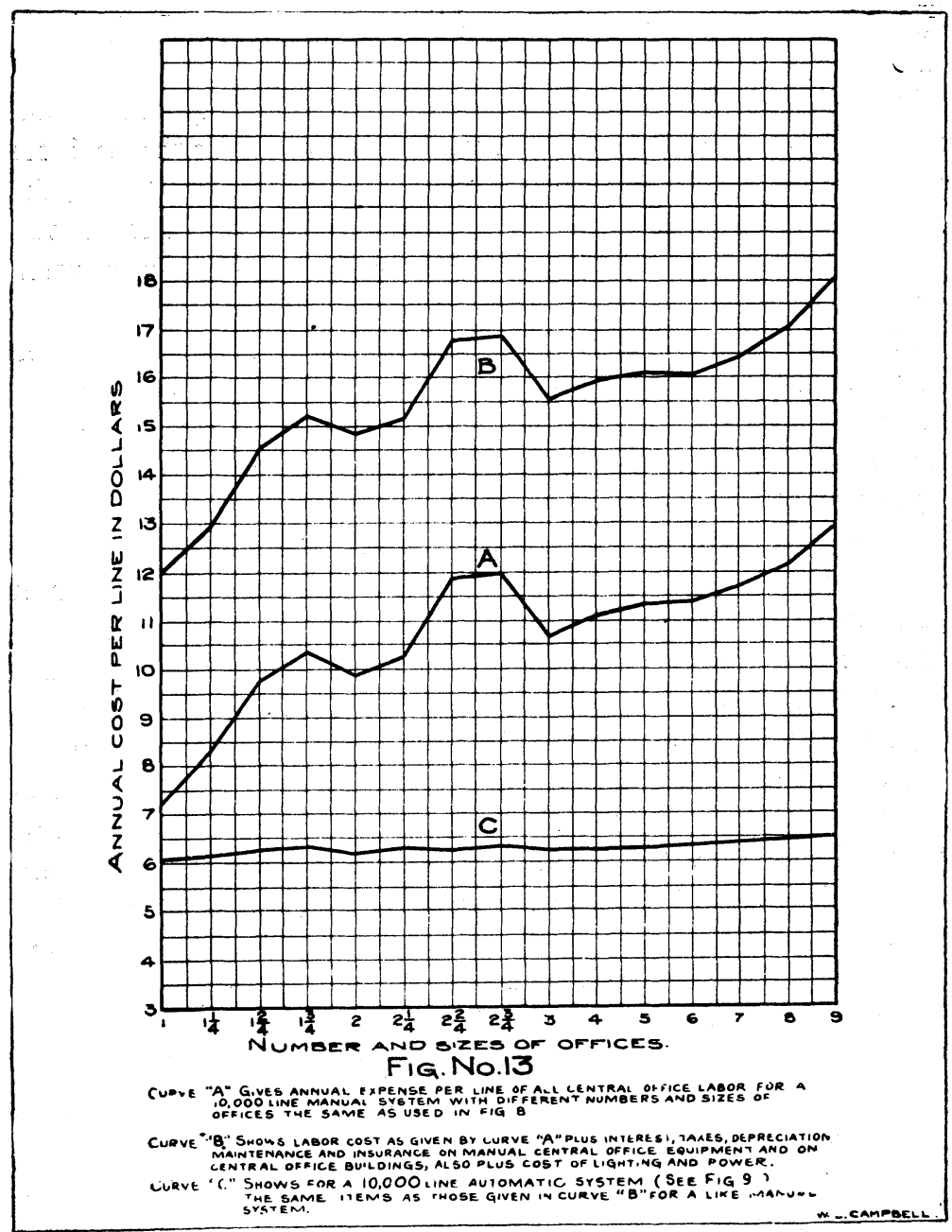

if division is not carried too far. It is, of course, necessary to make a thorough engineering study of each apparently suitable location for a branch office, to determine whether or not any real economy would result; but since the annual charges on subscribers' lines less than two miles long using No. 22 gauge 
cable conductors average about $\$ 2.50$ per mile, it will be seen that the saving in length of line will be less than the corresponding increase per line per annum in central office expenses (indicated by curve " B" in Fig. 13) except where the lines are comparatively long. Roughly speaking, an economical arrangement of the average divided manual system will include offices not much less than two miles apart.

Curve $C$ in Fig, 13 shows that division of automatic systems may be profitably carried much further on account of the slow

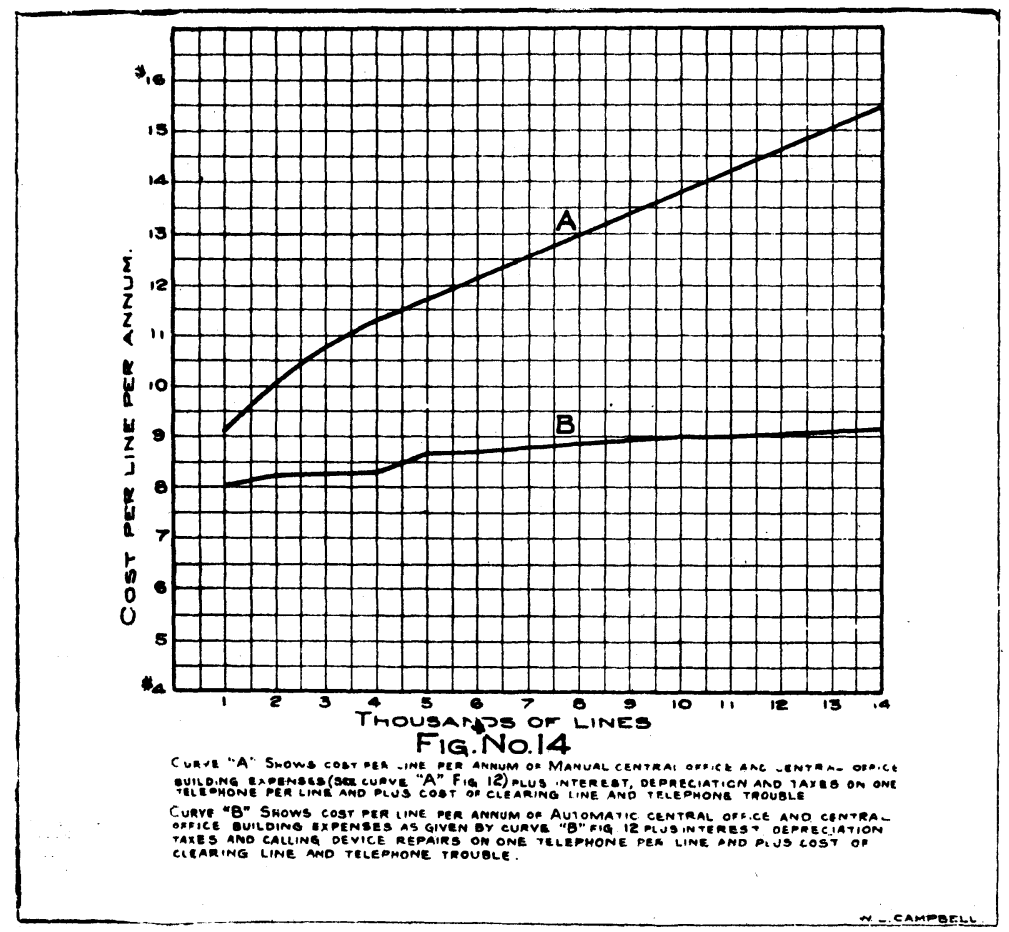

increase in central office expenses resulting from adding to the number of offices.

The writer hopes that he will be pardoned if, before leaving the subject of operating expenses, he pauses to call attention to curves $A$ and $B$, Fig. 14, which include the office expenses as given by curves $A$ and $B$, Fig. 12, plus the annual cost per line of clearing line and telephone trouble; and plus the annual charges for interest, depreciation, and taxes on one telephone per line. 
In calculating depreciation, the life of the telephones for both systems has been taken to be 10 years. It might appear unreasonable at first thought to believe that the more complicated automatic telephone has as long a life as the simpler manual instrument, but experience shows that the parts of a telephone which depreciate most rapidly are those which are handled by the user, knocked and rubbed against by passers-by and mischievous persons; also that the parts which must be kept highly finished, because they are exposed to view, are most quickly affected not only by human contact but by sunshine, dampness, etc. Consequently, since very little more of an automatic telephone than of a manual telephone is exposed, and since the calling device, which represents about $40 \%$ of the value of the instrument, is locked inside the case, where it is subject only to wear and tear of legitimate service, which it will successfully withstand for at least 15 years, the writer has concluded that automatic telephones could reasonably be considered to be longer lived on the average than manual telephones. He has, however, as already stated, placed the two on the same basis.

The cost of material for repairs and renewals on automatic telephones is a little greater than for the manual. It was found by a thorough investigation that the cost of new parts peculiar to the automatic telephones amounts to $0.14 \%$ per annum. This difference has, therefore, been noted in comparing maintenance costs of the two systems in Fig. 14.

The cost of labor for keeping telephones in order is included in the curves in Fig. 14 and for automatic telephones is also shown separately in Fig. 15. No insurance on the telephones is included.

Returning to the subject of plant division and its results, there is still another point to be considered, namely, the effect of plant division on service. An investigation of this reveals what is a very serious objection to a multi-office manual system; because slower service, more mistakes by the operators, and, what is most aggravating to a telephone subscriber, more premature disconnections during conversation, are the inevitable results of having connections handled by two operators instead of by one. The good will of the telephone user is something which cannot be lightly considered in these days of keen telephonic competition. Unpopular service is not only a serious handicap in a contest with a rival company; but it also retards growth, invites higher taxes and hostile legislation, and often results 
in a general clamor for the regulation and reduction of rates. On the other hand, a record of giving service which meets with the general approval of its subscribers is an asset of inestimable value to any telephone operating company, and, in fact, is the best reason for the company's existence. We find, therefore, telephone managers, who are chiefly concerned in pleasing the public, pretty solidly arrayed against having manual systems split up, except where the number of stations is so great or the area covered by the system so large that rates would be excessive if one central office only were used. In fact, " no divided systems," was one of the battle cries of the leaders of the inde-

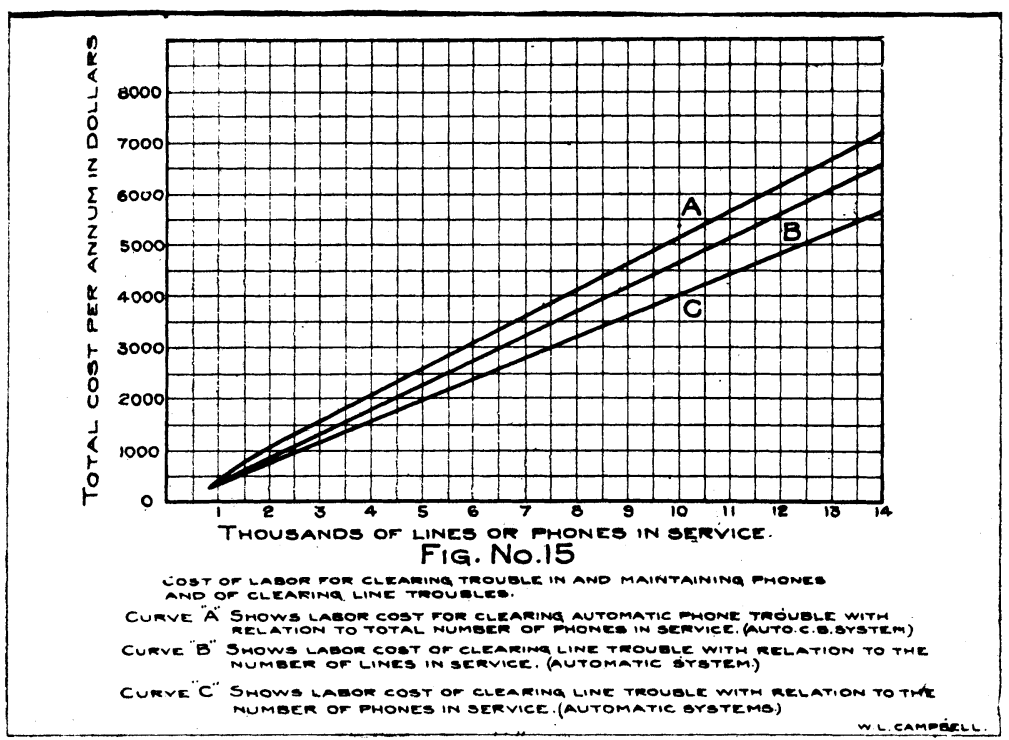

pendent telephone movement which has spread over the country so rapidly and so widely that its present magnitude baffles conception.

Increasing the number of offices in an automatic system does not appreciably affect the service. All calls are trunked anyhow, whether one office is used or many. Therefore, splitting up such a system does not add to the amount of trunking or in any way affect the speed and uniformity of service. The subscriber is not required to change his method of calling or to make more turns of his dial. No more automatic switches are necessary and a connection does not include any more switches 
in a divided system than in a single office plant. When the writer states that the service of a multi-office automatic system is on a par with that of a single office automatic system, he believes that he gives it the highest endorsement possible in the present state of the telephone art; for the companies operating automatic switchboards have demonstrated beyond question that they can give satisfactory service and furnish any special attention to which patrons of the girl-operated systems have been accustomed. Indeed, telephone users, who have had experience with both, almost universally prefer the automatic service to the manual. This fact is not only attested by all who have made an investigation, but has been publicly affirmed repeatedly in the reports of prominent public servants and engineers. For example, attention might be directed to the address delivered by Mr. Kempster B. Miller, before the International Electrical Congress at St. Louis, in 1904.

Not only has the writer not discovered any reasons which weigh materially against division of automatic systems, but he finds that the saving in the investment in cable, wire, and conduit would be even greater than in a manual system. First, because division may, as clearly shown, be carried much further without seriously affecting central office expenses, and secondly, because the number of trunk lines required for handling traffic between automatic offices is less than between similar manual offices. In other words, an automatic trunk will carry, on the average, more busy-hour calls than a manual trunk.

Curve $A$, Fig. 16, shows the call-carrying capacities which one of the largest manual telephone companies instructs its engineers to use in arriving at the number of trunks needed between proposed offices. As a rule, a manual trunk should not be expected to handle over 15 to 18 calls during the busy-hour even between rather large, well-managed offices; between small offices from 10 to 12 is all that can safely be depended upon. Reference, however, to curves $A$ and B, Fig. 4, shows that between automatic offices a considerably higher trunk-carrying capacity is experienced. The largest number of trunks per group almost universally used in automatic systems is 10 . Therefore, the curves in Fig. 4 are dotted above the line corresponding to 10 circuits per group. With groups of this size a minimum carrying capacity of 22.5 busy-hour calls per trunk is secured. This is a decided increase over the carrying capacity of manual trunks even where the latter are installed in groups 
of the greatest efficiency; that is, groups of about 73 circuits each. It would rarely, if ever, be possible to obtain such a large group if a manual plant were so divided that all offices were comparatively small, but in almost any multi-office system the majority of the trunks between offices can readily be placed in small groups of 10 trunks each. Consequently, in an

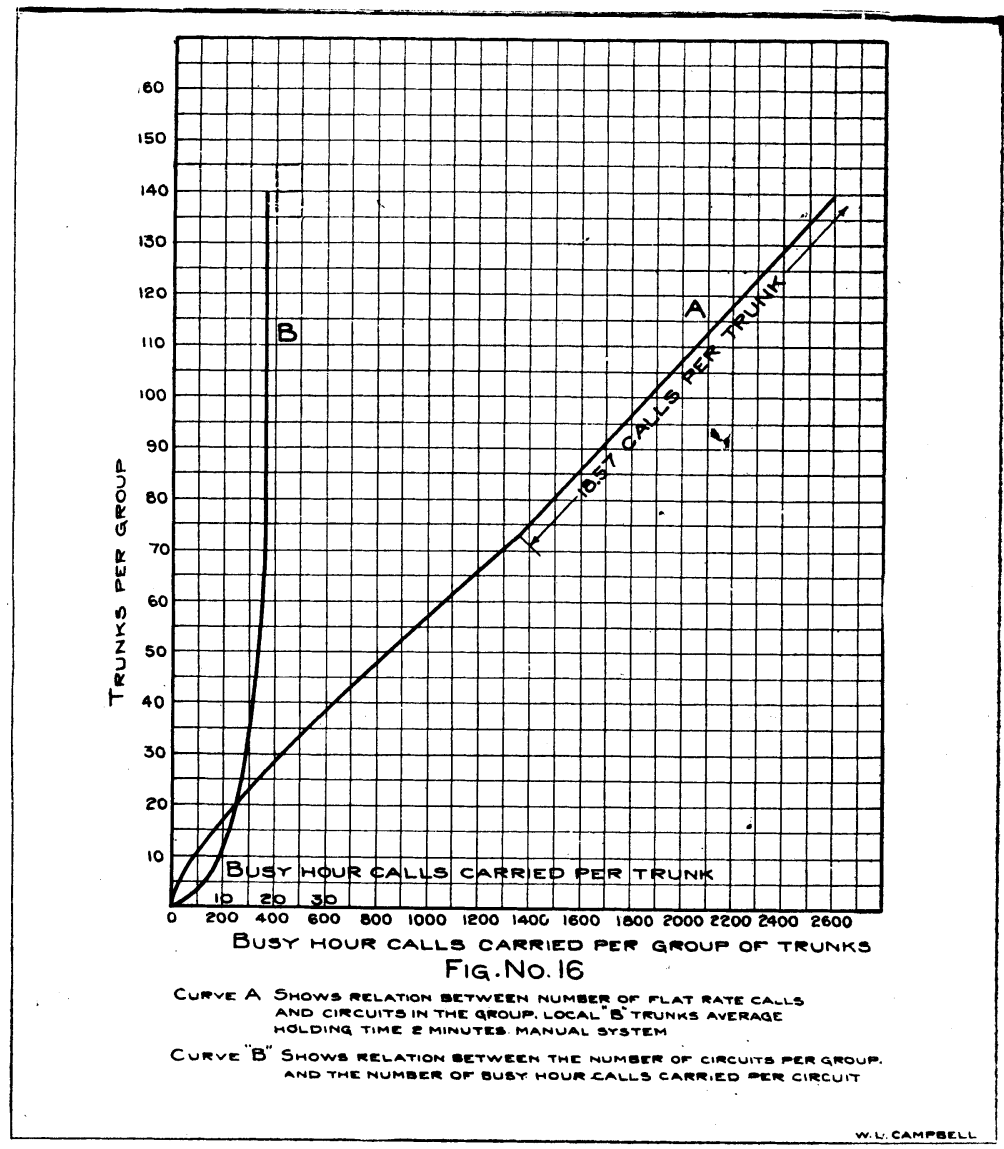

automatic multi-office system maximum efficiency is secured on nearly all of the trunks. This is illustrated by curve $D$, Fig. 9, which gives the average minimum carrying capacity per trunk for each of the different arrangements of the hypothetical 10,000line system. The average minimum number of busy-hour calls carried per trunk is, according to the curve, about 20.75, and the lowest figure is 19.3 for the nine office arrangement. Sup- 
posing, for the moment, that it be practicable to use this nineoffice arrangement in a 10,000-line manual system, the average number of busy-hour calls carried per trunk would be about 12 .

The small number of trunks that will carry the traffic between automatic offices even in a thoroughly divided system is illustrated by curve $E$, Fig. 9 , which shows the ratio on a percentage basis between the number of trunks and the number of subscribers' lines. With the largest number of offices considered this percentage is but 9.3 .

One reason for the increased efficiency of automatic trunks is found in the shorter length of time per connection. In manual practice it has been found that each trunk is occupied on the average at least two minutes per connection, whereas automatic experience proves that during the busy-hour a trunk is not occupied over 83 seconds per average connection. A subscriber to automatic service answers his telephone quicker and generally does not hold the line so long for conversation as does a manual subscriber; also, the disconnection is made much quicker in the automatic system. This feature of the quicker disconnection is especially helpful during the busy hours when manual operators are most likely to be rushed and consequently slow about pulling down connections. The interval of time that elapses between release of a trunk by one automatic selector and seizure of it by another need be, and often is, but a fraction of a second. This, too, helps to increase the carrying capacity of the trunks.

The writer was much interested while studying the efficiency of the trunks of the two systems to note the difference between the number of connections existing at the busiest moment of the day in manual and automatic offices. For example, in the central office of a busy manufacturing city in Ohio a count was taken every day for a week in January of one year to ascertain the maximum number of connections "up" in the various operators' positions at intervals during the busy hours of each day. The results for the busiest day are shown in curve $A$, Fig. 17. A few months after these observations were made the equipment of this office was changed to the automatic type. In the following January, one year after the original data were secured, counts were made every day for one week of the number of connections "up" during the busy hours in the automatic switchboard. The results for the busiest day are shown in curve $B$, Fig. 17 . It will be noted that the maximum per- 
centage of connections counted at one time on the manual was 7 while on the automatic it was but 4.36. Similar observations were made on a number of automatic plants, and, as already stated earlier in this paper, it was found that in busy automatic offices of 8000 or 10,000 lines, the maximum number of connections counted at the busiest moment did not exceed $4 \%$. In small offices of less than 1000 lines where erratic fluctuations of the traffic are more noticeable the maximum ran up to $4.7 \%$ in some instances.

A still higher trunk efficiency could often be secured in automatic systems if the trunk groups could be made larger than 10

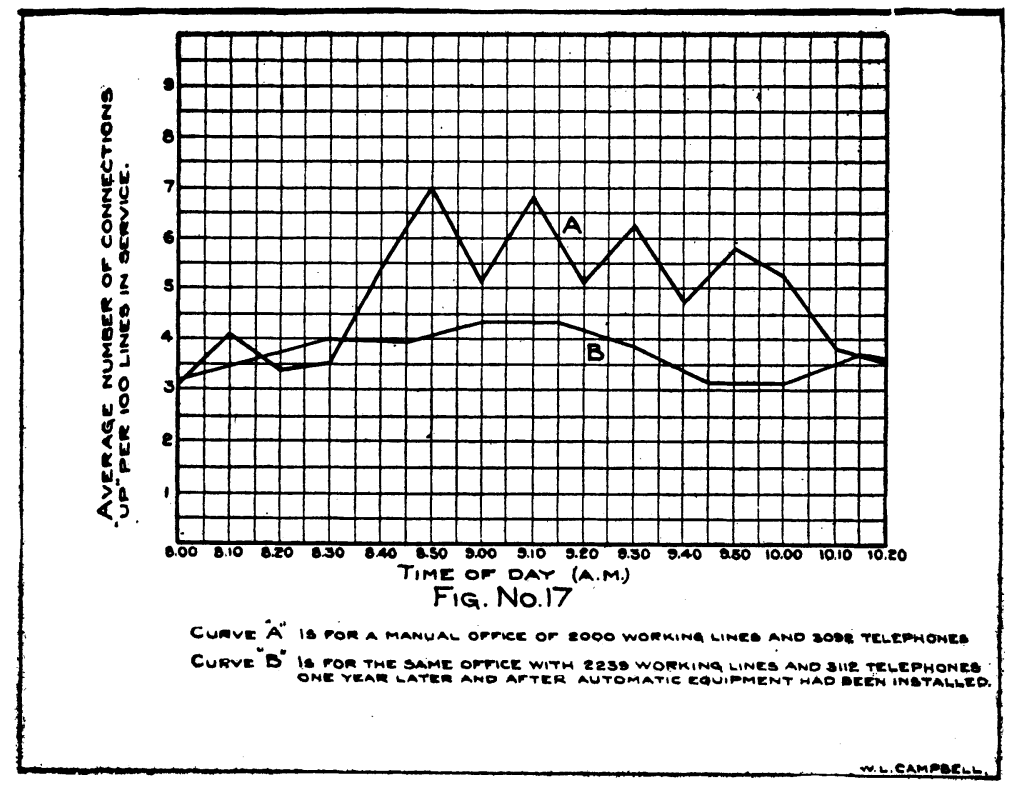

lines each without impairing the speed at which idle trunks are selected. This is shown by the dotted portions of curves $A$ and $B$, Fig. 4 , which give the carrying capacity per group and per circuit for groups up to 28 circuits each. On account of the fact that in an automatic system where the number of offices is comparatively large, and each office is comparatively small, the trunks are generally divided into a large number of small groups, and it is doubtful if there would be anything gained by making the maximum size of a group of trunks between offices greater than 20 circuits. Indeed in such a system many of the groups would contain considerably less than 20 circuits each. 
The manufacturers of automatic apparatus have recognized the possibilities of larger groups and are now testing equipment designed to enable them to put more lines in each. Since such equipment has not come into general use, however, it will not be considered further in this paper.

In endeavoring to form some conception of the methods used for introducing trunking of calls on a large scale between automatic offices, it is well to understand the difference between two general types of office that are being used for this purpose.

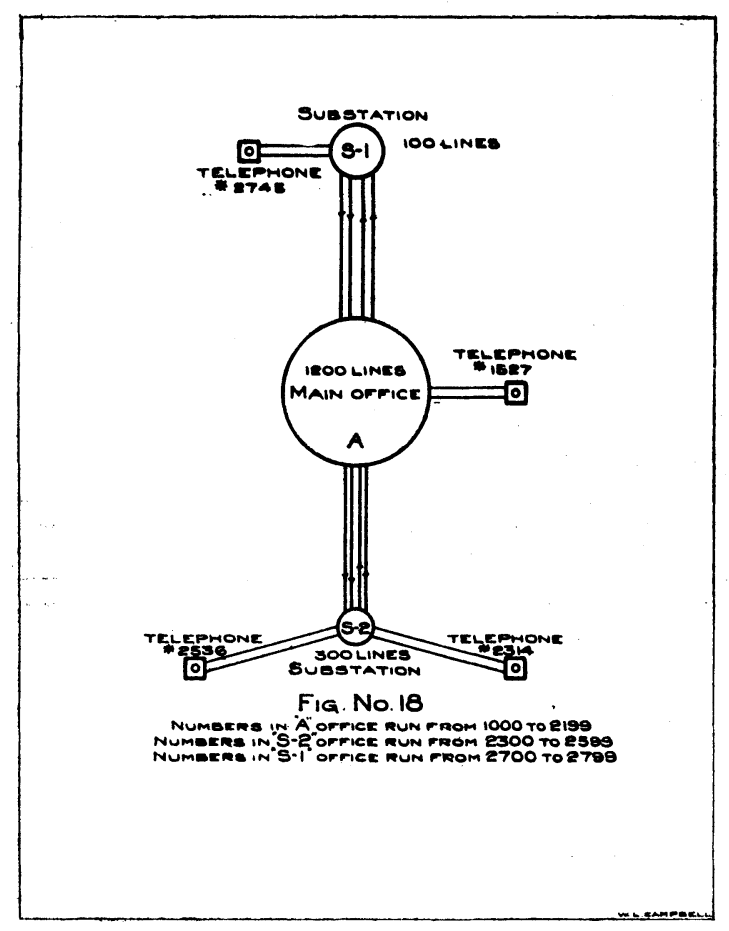

One is known as a "sub-station" or "district" office and the other as a "branch" office. The difference lies in that a substation contains line switches and connector switches but no apparatus for making local connections; that is, every originating call is trunked to a distant larger office containing the selector switches, whereas a branch office contains switches of all classes and completes within itself all local connections demanded. It will readily be seen, therefore, that a sub-station requires more outgoing and incoming trunks than a branch office. 
For an illustration of a system using sub-stations attention is directed to Fig. 18, in which $A$ represents a "main " office containing the equipment for 1200 lines. "A " contains also the first selector and second selector switches used by two substations $S-1$ and $S-2$. $S-1$ is represented as containing line switches and connector switches for 100 lines and $S-2$ is supposed to contain line switches and connector switches for 300 lines.

Calls would be handled as follows: suppose for example, a subscriber at telephone No. 2314, which is connected to substation $S-2$, to be calling No. 1527 connected to the main office $A$. The impulses sent over the circuit through the calling device of telephone No. 2314, would first operate a line switch at $S-2$, which would instantly extend the connection over an idle trunk to a first selector switch at $A$. This first selector switch would be operated by the impulses corresponding to the first digit " 1 " of the desired number, and, would extend the connection to a second selector, also located at $A$. This second selector, would be operated by the impulses corresponding to the second digit 5 of the desired number and would extend the circuit to a connector switch in the " 1500 group " at $A$. This connector switch would be operated by the impulses corresponding to the last two digits 2 and 7 of the desired number and would complete the connection to line and telephone No. 1527. Suppose again No. 2314 to be calling No. 2745 connected to the other substation $S-1$. A line switch at $S-2$ would be operated first, then a first selector and a second selector at $A$. This second selector would extend the connection over a trunk to a connector switch located at $S-1$. This switch would be operated by the impulses corresponding to the last two digits of the desired number, and would complete the connection to line and telephone No. 2745 .

Suppose again, No. 2314 to be calling No. 2536 connected to the same sub-station, $S-2$. In this case, a line switch at $S-2$ would, as before, extend the connection to a first selector switch at $A$. This switch would extend it to a second selector at $A$, which would extend it back over another trunk to a connector switch at S-2. This connector switch would complete the connection to line and telephone No. 2536. During such a conversation, therefore, two trunks would be occupied between the sub-station and the office through which it operates. This indicates that a sub-station is best adapted to a district where there is very little local telephonic intercourse, because every local connection occupies two trunks without any immediate benefit. 
The sub-station is also especially adapted to a small isolated district where the expense of a constant local attendant would not be warranted, and, where it is, therefore, considered advisable to install the simplest apparatus obtainable, with arrangements for supervision from the main office to which the sub-station trunks are connected. Under almost any conceivable condition a sub-station will require more trunks than a branch office, for several reasons: first, all calls must be trunked; secondly, there is one group of outgoing and one group of incoming trunks for each 100 lines connected to the sub-station; thirdly, in order to provide thorough supervision from the main office, each outgoing trunk contains three wires instead of two.

It is, therefore, seen that in considering the advisability of installing a sub-station instead of a branch office, the increased expenditure for trunk installation and maintenance should be weighed against the saving in cost of supervision and attendance.

When the proposed office is to be a small one, and the trunks to it are to be secured by converting the line cable at present entering the new office district into a trunk cable, there is often no immediate advantage in economizing in the number of trunks. To such conditions a sub-station is well suited even if the trunks are long and consequently expensive. It would appear, however, that in the present state of the art such an auxiliary to a "main" office would rarely be warranted if it contained over 500 lines.

A sub-station may often be used to much better advantage as an auxiliary of a branch office; that is, a branch may be installed at the center of a comparatively large district so that all trunks going out from or coming into the district will terminate at the centrally located branch office, then shorter and more numerous trunks may be run from this office to sub-stations located about it. As an illustration of this plan please refer to Fig. 19 in which $A$ represents an office of 5000 lines, $B$ a branch office of 1500 lines, $S-1$ a sub-station of 100 lines, and $S-2$ another substation of 300 lines auxiliary to the branch office. Calls would be handled as follows: suppose, for example that a subscriber No. 8712 connected to sub-station $S-2$ called telephone No. 2134 connected to office $A$. As No. 8712 operated his calling device his line switch at $S$-2 would instantly operate and connect his telephone over an idle trunk to a first selector 
switch in branch office $B$. This first selector would be operated as the subscriber's calling device transmitted the first digit (2) of the number being called, and would extend the connection of the calling telephone over a trunk to a second selector switch at $A$ office. The second digit (1) transmitted from the calling telephone would operate this second selector and extend the connection to a connector switch also located at $A$. This connector switch would be operated by the last two digits (:3 and 4$)$ of the number called, and would complete the connection

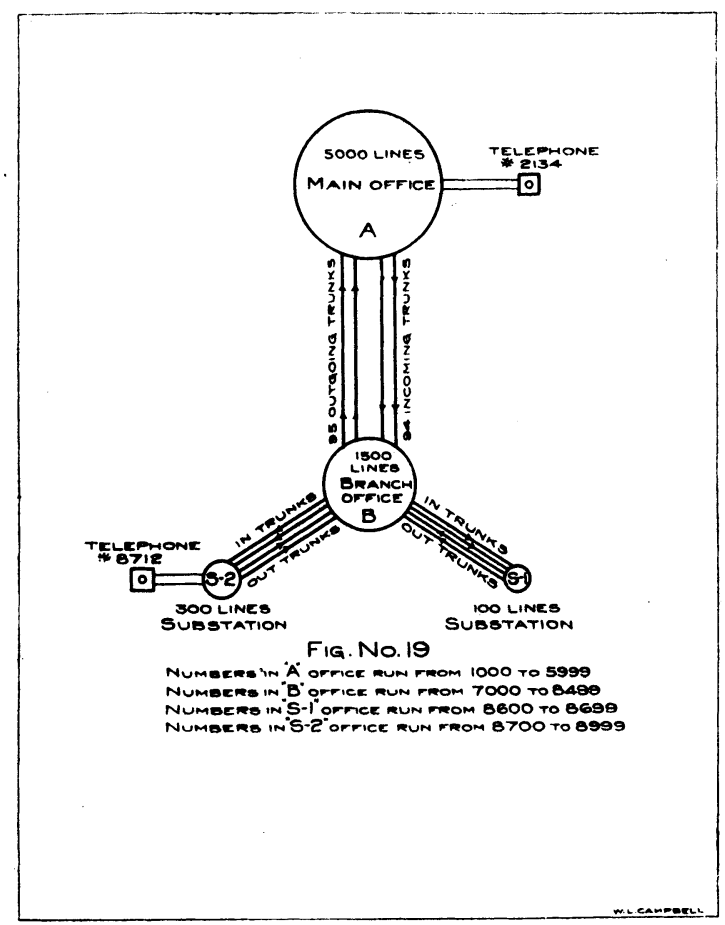

to the line and telephone No. 2134. It might be of interest to note in passing that the current for the transmitter of the calling subscriber would be furnished from the battery located at $B$ and the current to the called subscriber's transmitter from the battery located at $A$. If the call should proceed in the reverse direction, that is, if No. 2134 connected to $A$ should call No. 8712 connected to $S-2$, then the operation of a line switch and a first selector switch at $A$ would extend the connection over a trunk to a second selector at $B$ which would in turn extend 
it to a connector switch at S-2. This connector switch would complete the connection to line and telephone No. 8712 .

Supposing the number of calls made per line per day in this 6900 line system to be 16 , and the number of busy hour calls to be one-eighth of the total, and that the " community-ofinterest" can in all cases be taken care of by the factor 0.75 , then the number of incoming trunks necessary to $B$ from $A$ would be 94 , and the outgoing trunks to $A$ from $B$ would be 95 , a total of 189 . This number is $9.9 \%$ of the total of 1900 lines in the branch office district. The number of pairs of wires necessary for incoming and outgoing trunks, supervision, furnishing ringing current, charging substation battery and all other purposes between $B$ and $S-2$ would be 78 ; that is, $26 \%$ of the 300 lines connected to the sub-station, and between $B$ and $S-1$ would be 28 pairs, which equals $28 \%$ of the number of subscribers' lines connected to that substation.

In order to demonstrate the advantage that there may be in making the office $S-2$, for example, a sub-station instead of a "branch" office, the writer would direct attention to Fig. 20, in which is represented the same system as that in Fig. 19, except that the office $S-2$ is now considered to be a branch office of "B". S-2 would now contain first selector and second selector switches in addition to the line switches and connector switches. There would be no difference in the mode of operation so far as incoming calls to $S-2$ were concerned, but there would be a difference in the method for handling outgoing calls; also all local connections would be completed inside of the $S-2$ office. The principal difference in the outgoing connections would be that connections from $S-2$ to $A$, instead of passing through switches at $B$ would be trunked direct from the first selectors at $S-2$ to second selector switches at $A$. The effect of this would be to increase the number of groups of trunks and consequently the number of circuits necessary between $A$ and the $B$ districts, so that with the particular case illustrated in Fig. 20 the total number of trunks between $A$ and $B$ would be increased by 15 , while a reduction of only 12 circuits would be secured between $B$ and $S-2$. It is, therefore, readily seen that if the distance from $A$ to $B$ is equal to, or greater than, the distance from $B$ to $S-2$, that the branch office scheme in Fig. 20 would require more trunk mileage than the sub-station scheme in Fig. 19. The writer believes that this fairly illustrates the advantage that there may often be in using the sub-station as an auxiliary of a branch office. 
As an illustration of how trunking of calls is done in a larger automatic system, Fig. 21 shows a rough skeleton of a 50,000line system. This contains 5 main offices, $A, B, C, D$, and $E$, of which $A$ has 8 branch offices and the other main offices each have 5 branch offices. Since this system has an ultimate capacity of 100,000 lines, all numbers would have five figures, but, as is customary, in place of the first figure a letter is used, which not only makes the number easier for the subscriber to remember, but also designates the office to which the number

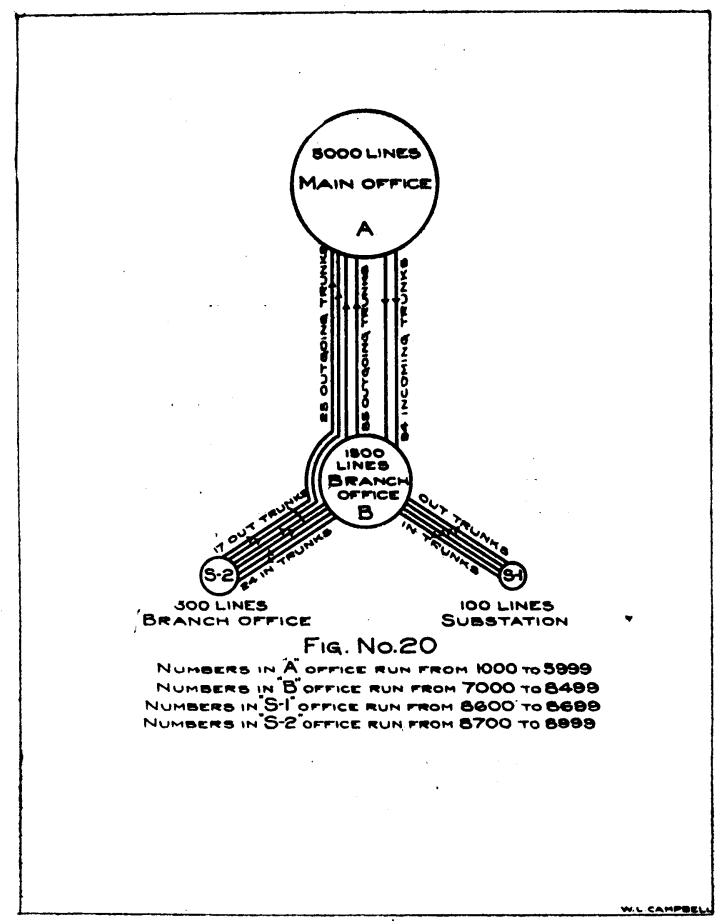

belongs. It is supposed that the main office $A$ contains equipment for 2000 lines, the numbers of which run from 1000 to 2999 ; and that each of its branches contains equipment for 1000 lines, the numbers in $A-3$ running from $3000-3999$, in $A-4$ running from 4000 to 4999 , etc. Each of the other main offices is also supposed to contain equipment for 2000 lines, the numbers of which run from 1000 to 2999 in each. Of course, there is a letter prefix to each number corresponding to the office to which the number belongs. Each branch of the offices $B, C, D$ and $E$ 
is supposed to contain 1000 lines. The numbers in $B-4$, for example, run from 4000 to 4999 , those in $B-5$ run from 5000 to 5999 , etc.

Connections in the system would be handled as follows:

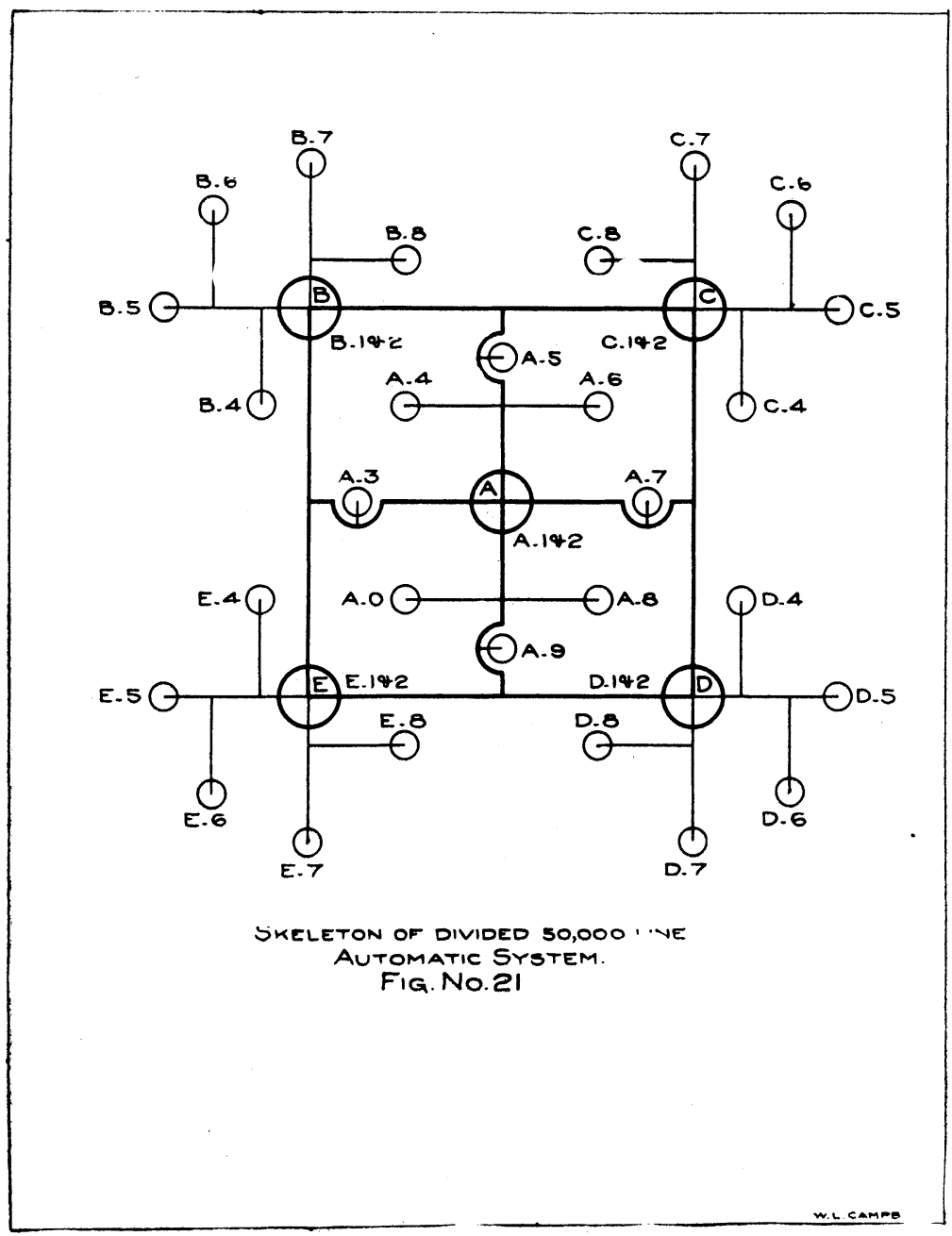

suppose a subscriber $E-7234$ connected to branch office $E-7$ called $A-5124$ connected to the branch office $A-5$. The first movement of the subscriber's calling device would operate his line switch and connect his line to an idle first selector in his own exchange, E-7; then when the calling device sent in a num- 
ber of impulses corresponding to the No. A, his first selector would be operated and would pick out an idle trunk to a second selector in exchange $A$. The second set of impulses corresponding to the figure 5 sent in by the calling device would operate the second selector at $A$ and extend the connection over an idle trunk to a third selector in the office $A-5$. The next set of impulses corresponding to the 1 of the desired number would operate a third selector at $A-5$, which would extend the connection to a connector switch in the proper " 100 group " at $A-5$. This connector would be operated by the impulses corresponding to the last two digits of the desired number and would complete the connection to line and telephone $A-5124$.

It may be noted that on this call the connection to $A-5$ passes through the main exchange $A$. This would be true of every call incoming into the $A$ district; that is, all trunks incoming into the district would terminate in second selectors in the $A$ office. These second selectors would extend each incoming connection to a third selector located at the $A$ main office, or at the branch corresponding to the thousands digit of the particular number being called. This concentration of the incoming circuits simplifies the trunking arrangement and also reduces considerably the number of trunks entering the district, because the number of groups of incoming trunks would be nine times as great if each of the nine offices received its calls, coming from outside the district, direct instead of having them come through the main distributing office $A$. It should be noted on the other hand that the outgoing call from $E-7$ does not operate any switch at its main office $E$. It would probably be preferable, however, to have the trunk pass through the cross connecting frame at $E$. In a similar manner all outgoing trunks from each of the branch offices of $E$ district could be terminated on the distributing frame at $E$, and there be cross-connected to what might be called a "through trunk cable" to each of the other main offices. If a subscriber connected to any office in the $A$ district should call a number connected to an office in $E$ district the incoming trunk to $E$ district would terminate in a second selector switch at main office $E$, and would be passed on by it to the desired branch office or thousand group. - In the skeleton diagram no trunk cables are shown interconnecting the branch offices of a district; for instance, no interconnection is shown between E-6 and E-7. If desired such trunks could be put in, or the outgoing trunks from all the branch offices 
of $E$ may, as already stated, be run to the main central office and there be cross connected on a distributing frame. This would in many cases be the most economical arrangement, because with division carried to the extent that it is in this diagram the number of trunks required between $E-6$ and $E-7$ would be comparatively small. A call from a subscriber at $E-7$ to a subscriber connected to $E-6$ would operate a line switch, first selector and second selector at E-7 and a third selector and connector at $E-6$ so that it is not necessary that the connection should pass through the main office $E$.

If a manual system should be divided up in the manner shown in Fig. 21, supposing for the moment that such a division would be practical with equipment of that type, then the branch office $E-7$, for instance, would have 32 different groups of outgoing trunks; that is, one group for each of the other offices in the system, and would have the same number of groups of incoming trunks. With the automatic branch office arrangement, $E-7$ has but 10 groups of outgoing trunks; that is, one group to each of the other district main offices and one group to each other "thousand section" in use in its own $E$ district. $E-7$ would have but 5 groups of incoming trunks; that is, one group from each of the other offices in the $E$ district. It is, seen, therefore, that by using the main offices at centers of comparatively large districts and then surrounding each main office with smaller branches, all subscribers lines may be made very short and the use of the "through" trunks between the main offices for interconnecting districts makes the trunking system comparatively simple.

It is probably unnecessary to add that in planning such a system as is represented by Fig. 21, a careful engineering study should be made for each branch office to determine whether the trunk mileage required would make a "branch" office or a "sub-station" the most economical arrangement.

One of the peculiarities of the telephone business, especially when there is competition, is that an operating company is compelled to take on the new business offered. It must keep up with its rival or drop out of the race. A user of electric light doesn't care how many other customers are connected to the same plant that he is, but a telephone user is, of course, very much attracted by the larger of two lists of subscribers. Unfortunately a one-office plant is somewhat like a water or gas plant, in that new customers cannot be constantly added 
by simply connecting their service pipes to the mains originally installed. Some day a point is reached when the mains are supplying all the flow of which they are capable and it is necessary to go back to headquarters, dig up the streets anew, and put in more mains or larger ones. So in a one-office telephone system, if the growth is more rapid than anticipated, as it often is, or if the growth of the city takes place in an unexpected direction, as it frequently does, it becomes necessary to remodel the cable and wire plant to suit the new distribution of business.

A one-office telephone plant sometimes must be almost entirely rebuilt within a few years of its installation in order to adapt it to a shifting of population, or to make it adequate for the customers unexpectedly demanding service.

With a multi-office automatic system this need not be done. If an unexpected demand for telephones develops in a certain section of the city, it is not necessary to put in more conduits and cables or to replace present cables with larger ones to take care of the demand, but the situation is readily and practically met by putting in a substation or a branch office in the congested district. The present line cables running to the district may be used as trunk cables to the new office. Thus the traffic carrying capacity of the cable and conduit plant reaching any district may be greatly multiplied without any additional expenditure for cable or duct. Consequently, one of the most attractive features of an automatic multi-office system is that it affords a stable value to the investment in wire, cable, and conduit. 